\title{
Towards an Interest-Free Islamic Economic System
}

\author{
WAQAR MASOOD KHAN \\ Chief Economist and Vice President \\ Bankers Equity Limited, Karachi, Pakistan
}

\begin{abstract}
Rigorous mathematical techniques are used to compare the Islamic financial system based on variable return scheme (VRS) with the traditional one based on fixed return scheme (FRS). It is shown, under certain assumptions which include risk aversion on the part of investors, that the Pareto optimal contract is the VRS. Also VRS spreads risks more evenly than FRS allowing more risk taking in the economy. The domination of the real world by FRS, i.e. debts contracts, is shown to be caused mainly by informational asymmetry and higher monitoring Costs in case of VRS. But these costs are not prohibitive. The more effective the methods of monitoring and the higher the level of honesty on the part of economic agents, the more superior the Islamic financial system would prove to be in practice.
\end{abstract}

\section{Introduction}

Elimination of Riba is central to a reorganization of financial system on the basis of Islamic principles. Although adoption of a given Islamic code can never be conditional on the result of an economic benefit-cost exercise it will still be useful in learning the measures policy makers should take to minimize associated costs. The institution of Riba is deeply embedded in the modern financial system. Accordingly, the job of Islamic scholars to devise a system which can smoothly replace the modern system is little more than formidable.

In this paper* we have rigorously investigated the implications of prohibiting interest from the economy. The main contribution of this paper is that the prohibition problem is discussed in the mainstream economics framework. The problem essentially lies in the domain of the theory of contracts and 'economics of information'. Accordingly our framework relates to these two areas of economics.

* This work is part of Ph.D. dissertation at Boston University. I am thankful to the Members of my Committee, Professors Michael Manove, Asad Zaman (Columbia University), Oldrich Kyn and Ingo Vogal sang. I assume the responsibility for all errors and omissions and the views expressed herein. 
The paper is divided into two parts. In Part I we discuss implications of moving to wards the new system and in Part II we discuss how the results of Part I change due to a major change in the environment of Part I. All proofs are contained in the appendix.

\section{PART I \\ Implications of Prohibiting Debt Financing}

The objective of this part is to develop a framework that would allow us to compare the Islamic financial scheme with the traditional one. This would then be helpful in drawing conclusions about the prohibition of interest from the economy.

A financial system is simply a collection of a number of contracts. The nature and characteristics of these contracts define a given financial system. Accordingly, we identify a given system by the type of contract it offers to the market. An Islamic financial contract does not allow for a fixed return over and above the principal amount loaned. Thus we identify a non-Islamic contract as one which requires from the borrower a fixed return over and above the principal amount. A debt contract is one example of such a contract and we use this as a prime representative of the non Islamic set of contracts. On the other hand, a contract which stipulates sharing of return from the enterprise made out of loaned money is taken to be an Islamic financial contract. The well-known mudarabah contract is the prime representative of Islamic set of contracts. These definitions are made more precise in section II.

In section II we start off by giving a careful description of the environment under which our analyses are undertaken. This is done by specifying the assumptions of the model.

Under a given set of assumptions we have shown that the Islamic scheme is superior to the traditional scheme. This is one of the fundamental results of this paper. Given the significance of this result, it is imperative that one should be very clear about the underlying conditions. Thus section III is fully devoted to a critical examination of the assumptions of our model.

We conclude that the result is fairly robust and can only be reversed through significant changes in the environment of the model.

\section{Assumptions, Basic Model and Results}

For any theory a careful specification of the environment in which the theory is applicable is an essential prerequisite. Like any other theoretical work we have simplified the economic scenario by abstracting from real world complications. We, however, will critically examine the underlying assumptions behind the results of our model.

Let us first outline the assumptions governing the environment of our model. These are: 
i) There is one financial institution called a lender.

ii) The supply of loanable funds is fixed.

iii) There are investors in the economy demanding identical loans.

iv) The credit market clears.

v) The project's performance is independent of the financing decision.

vi) The projects of different investors are uncorrelated.

vii) Investors are risk averse.

viii) Both the lender and a typical investor have identical beliefs about the probability distribution of the project return and both can observe it costlessly.

\section{Basic Model}

Let $\mathrm{L}$ be the fixed supply of loanable funds, then (iv) implies that:

$$
\mathrm{zn}=\mathrm{L}
$$

where $\mathrm{n}$ is the number of investors and $\mathrm{z}$ is the size of the loan.

Let $z R_{i}$ be the return of the ith investor when he invests $z$. We assume that $R_{i}$ is a random variable which is identically and independently distributed across different projects with the density $\mathrm{f}(\mathrm{r})$. For simplicity we restrict $\mathrm{R}$ to take only the positive real values. Finally $R$ has a finite first two moments, namely its mean, $E(R)$ and variance $\operatorname{VAR}(\mathrm{R})$.

Note that the above formulation implies constant returns to the loan size. This is dictated by the simplicity achieved in modelling. There might be increasing returns to the loan size but we ignore it in order to keep our analysis manageable.

Before we define the two schemes formally let us make few remarks. The traditional financial scheme we have in mind roughly works as follows: the lender transfers a certain amount of money, called principal, to the borrower on the condition that the principal and a fixed percentage return on the principal is payable at a future date. Although these payments are stipulated as fixed amounts, it is understood in many cases by both parties that if the earnings fall below the required payments then a lesser amount will be paid. In the present framework we have lumped all types of fixed payments into a single fixed payment that can be thought of as the principal plus the interest. Let D denote this fixed payment; then if $\mathrm{R}$ is greater than $\mathrm{D}$ then the lender will receive $\mathrm{D}$; otherwise it is understood that the lender will receive everything, i.e. the entire R.

On the other hand the Islamic scheme is the well-knowr mudarabah scheme. Thus the lender under this scheme would require a share in the return from the project. In case of zero return no party gets anything. The mudarabah scheme is no limitation to our analysis. The definition of Islamic scheme we use can incorporate a musharakah (partnership) scheme as well. In such a scheme part of the capital is brought by the investor himself. To show this assume that each investor bring an identical amount of the own capital, say $Z_{1}$ and borrows $Z_{2}$. Assuming further that both the own capital and borrowed are necessary to undertake the project, one can formulate a return function.

$$
\mathrm{R}\left(\mathrm{z}_{1}, \mathrm{Z}_{2}\right)=\mathrm{Z}_{1} \mathrm{Z}_{2} \mathrm{R}_{\mathrm{i}}
$$

for each investor. All results in the paper will carry over by letting $\mathrm{Z}=\mathrm{Z}_{1} \mathrm{Z}_{2}$. 
It is important to note at this stage that none of the two schemes we consider requires a collateral from the investor. In other words the lender accepts a default from the investor. In practice this is rarely true of the debt scheme since many of these loans are secured against a collateral. We will say more about it later in this part.

In our subsequent discussion we call the traditional scheme as Fixed Return Scheme (FRS) and the Islamic Scheme as the Variable Return Scheme (VRS). We now formally define the two schemes:

\section{Definition}

(FRS) A financial contract which specifies the following payoffs for the lender and the investor, respectively, is FRS:

$$
\mathrm{P}_{\mathrm{i}}^{\mathrm{F}}=\mathrm{z}\left(\min \left(\mathrm{R}_{\mathrm{i}}, \mathrm{D}\right)\right) ; \quad \mathrm{Y}_{\mathrm{i}}^{\mathrm{F}}=\mathrm{z}\left(\max \left(\mathrm{R}_{\mathrm{i}}-\mathrm{D}, 0\right)\right)
$$

Note that $\mathrm{P}_{\mathrm{i}}^{\mathrm{F}}$ and $\mathrm{Y}_{\mathrm{i}}^{\mathrm{F}}$ are random variables and their distribution is determined from the distribution of $\mathrm{R}_{\mathrm{i}}$. The aggregate payoff to the lender is given by:

$$
\mathrm{P}^{\mathrm{F}}=\sum_{\mathrm{i}=1}^{\mathrm{n}} \mathrm{z}\left(\min \left(\mathrm{D}, \mathrm{R}_{\mathrm{i}}\right)\right)
$$

\section{Definition}

(VRS) A financial contract which specifies the following payoffs to the lender and the borrower, respectively, is VRS:

$$
\mathrm{P}_{\mathrm{i}}^{\mathrm{V}}=(1-\mathrm{a}) \mathrm{zR}_{\mathrm{i}} ; \mathrm{Y}_{\mathrm{i}}^{\mathrm{V}}=\mathrm{az} \mathrm{R}_{\mathrm{i}} \quad \text { where } \quad 0<\mathrm{a}<1
$$

The aggregate return to the lender is given by:

$$
\mathrm{P}^{\mathrm{V}}=\mathrm{z} \sum_{\mathrm{i}=1}^{\mathrm{n}}(1-\mathrm{a}) \mathrm{R}_{\mathrm{i}}
$$

Given the specification of these two contracts our problem is to see which contract will be preferred in the credit market. We are interested in that contract which is Pareto optimal. This problem can be attacked in several ways. For instance we can assume that the lender is risk neutral and accordingly looks only at the expected return from the two contracts. But then he can choose a and D such that his expected return from the two schemes is identical. Then at this point the choice of the contract depends on the preference of a typical investor.

Another approach would be to find the pair (a, D) so that a typical investor has identical utility across two contracts. Then at this point we can see the preference of the lender for the two schemes.

We take the first approach without assuming that the lender is risk neutral. However we utilize the law of large numbers in looking at the lender's behaviour. 


\section{Some Asymptotic Results}

In the following two lemmas we would look at the behavior of expected payoff to the lender as he partitions the total supply of loanable funds in the finest possible way. These two lemmas would be essential in determining a lender's attitude toward the financial schemes.

Lender's expected payoff under FRS is given by:

$$
\mathrm{E}\left(\mathrm{P}^{\mathrm{F}}\right)=\mathrm{z} \sum_{\mathrm{i}=1}^{\mathrm{n}} \mathrm{E} \min \left(\mathrm{R}_{\mathrm{i}}, \mathrm{D}\right)=\mathrm{L} \cdot \mathrm{E} \min \left(\mathrm{R}_{\mathrm{i}}, \mathrm{D}\right)
$$

while the variance is given by:

$$
\begin{aligned}
\operatorname{Var}\left(\mathrm{P}^{\mathrm{F}}\right) & =\operatorname{Var}\left(\sum_{\mathrm{i}=1}^{\mathrm{n}} \mathrm{z} \min \left(\mathrm{R}_{\mathrm{i}}, \mathrm{D}\right)\right) \\
& =\mathrm{z}^{2} \mathrm{n} \operatorname{Var}\left(\min \left(\mathrm{R}_{\mathrm{i}}, \mathrm{D}\right)\right) \\
& =\mathrm{z} \mathrm{L} \operatorname{Var}\left(\min \left(\mathrm{R}_{\mathrm{i}}, \mathrm{D}\right)\right)
\end{aligned}
$$

Thus $\mathrm{P}^{\mathrm{F}}$ is distributed as:

$$
\mathrm{P}^{\mathrm{F}} \sim\left\{\mathrm{L} . \mathrm{E} \min \left(\mathrm{R}_{\mathrm{i}}, \mathrm{D}\right) ; \mathrm{z} L \operatorname{Var} \min \left(\mathrm{R}_{\mathrm{i}}, \mathrm{D}\right)\right\}
$$

Now we have the following:

Lemma 1. Let $\mathrm{P}^{\mathrm{F}}$ be a sequence of identically and independently distributed random variables with the moments given in (8) then

$$
\mathrm{P}^{\mathrm{F}} \rightarrow \mathrm{LE} \min \left(\mathrm{R}_{\mathrm{i}}, \mathrm{D}\right), \text { as } \mathrm{z} \rightarrow 0
$$

Proof: In Appendix 1

This lemma determines the behavior of the lender's payoff as he partitions the available funds into smaller loans. What it says basically is the fact that if the lender extends smallest possible loans then he can reduce the probability of default from any one investor to an arbitrarily small level. In other words, in the presence of a large number of investors if one investor defaults then its effect on the lender's expected payoff is negligible.

Similarly lender's expected payoff under the VRS is given by:

$$
\mathrm{E}\left(\mathrm{P}^{\mathrm{V}}\right)=\mathrm{L}(1-\mathrm{a}) \mathrm{E}\left(\mathrm{R}_{\mathrm{i}}\right)
$$

and the variance of return is given by:

$$
\begin{aligned}
\operatorname{Var}\left(\mathrm{P}^{\mathrm{V}}\right) & =\mathrm{z}^{2} \mathrm{n}(1-\mathrm{a}) \operatorname{Var}\left(\mathrm{R}_{\mathrm{i}}\right) \\
& =\mathrm{z} \mathrm{L}(1-\mathrm{a}) \operatorname{Var}\left(\mathrm{R}_{\mathrm{i}}\right)
\end{aligned}
$$


Thus $\mathrm{P}^{\mathrm{V}}$ is distributed as:

$$
\left(10^{\prime}\right) \mathrm{P}^{\mathrm{V}} \sim\{\mathrm{L}(1-\mathrm{a}) \mathrm{E}(\mathrm{R}) ; \mathrm{z} \mathrm{L}(1-\mathrm{a}) \operatorname{Var}(\mathrm{R})\}
$$

And we have a similar result like in lemma-1 for the sequence of random returns $\mathrm{P}^{\mathrm{v}}$ under VRS.

Since the lender is not assumed to be risk neutral we need to look at his expected utility in order to determine his preference for any contract. Let $\mathrm{U}_{b}$ be the utility function of the lender. We assume that $\mathrm{U}_{b}$ is continuous. The following lemma determines a lender's utility level under both FRS and VRS:

Lemma 2. Let $\mathrm{p}^{\mathrm{F}}$ and $\mathrm{p}^{\mathrm{v}}$ be the two sequences of independent and identically distributed random variables converging in probability to $\mathrm{E}\left(\mathrm{P}^{\mathrm{F}}\right)$ and $\mathrm{E}\left(\mathrm{P}^{\mathrm{V}}\right)$ respectively. If $U_{b}$ is a continuous function then:

$$
\begin{aligned}
& \mathrm{U}_{\mathrm{b}}\left(\mathrm{P}^{\mathrm{F}}\right) \rightarrow \mathrm{U}_{\mathrm{b}}\left(\mathrm{E}\left(\mathrm{P}^{\mathrm{F}}\right) \text { as } \mathrm{z} \rightarrow 0\right. \\
& \mathrm{U}_{\mathrm{b}}\left(\mathrm{P}^{\mathrm{V}}\right) \rightarrow \mathrm{U}_{\mathrm{b}}\left(\mathrm{E}\left(\mathrm{P}^{\mathrm{V}}\right) \text { as } \mathrm{z} \rightarrow 0\right.
\end{aligned}
$$

Proof: In Appendix 1

This is a very important and useful lemma. It establishes the fact that if a lender has a continuous utility function then he would only look at the expected payoff from the two schemes. Notice that the assumptions underlying the two lemmas are much less restrictive than assuming risk neutrality on the part of the lender. The crucial requirements for the lemmas are uncorrelated investment projects and a continuous utility function for the lender. There is another important requirement for these lemmas to hold: lender's ability to partition the total supply in the finest way. This essentially requires that the lender be able to extend arbitrarily small loans. One can easily make a case for a critical loan size determined by the associated cost of loan.

There are two things to be noted. First though we require a fine partition to the available funds, it doesn't mean a very small loan. Indeed we can easily show that for each positive e there is a $\mathrm{z}$ such that for all $\mathrm{z}<\mathrm{z}$ the probability of realizing the expected return is greater than (1-e). Second, if this procedure fails we can expect, in the presence of one lender, that the relative loan size Z-L will still be very small.

Thus the preference of the lender across two contracts can be determined by looking only at the expected payoff. Consequently the lender will be indifferent across two schemes if he is offered the same expected payoff. Indeed if the bargaining process for choosing a financial contract is continuous, in the sense to be made precise below, there will always exist a situation such that the lender is indifferent between two schemes. The following lemma formally gives this fact:

Lemma 3. Fix D and let $0<\mathrm{a}<1$. Then there exists an $\mathrm{a}^{*}$ such that:

Proof: In Appendix 1

$$
\mathrm{E}\left(\mathrm{P}^{\mathrm{F}}\right)=\mathrm{E}\left(\mathrm{P}^{\mathrm{V}}\right)
$$


There is an important corollary to lemma-3. This will show that a lender will strictly prefer a scheme which offers a higher expected payoff:

Corollary 1. For all $\mathrm{a}<\mathrm{a}^{*}$ lender strictly prefers VRS

Proof: In Appendix 1

In the presence of lemmas 1-3 it is clear that the choice of a financial contract hinges upon the preference of a typical investor. We will now show that the investor's preference for the contract is determined by his attitude toward risk. If we let a typical investor be risk neutral then we have the famous result:

Proposition 1. (Miller-Modigliani) Suppose the lemmas 1-3 are true. If a typical investor is risk neutral then the choice of a financial contract is irrelevant.

\section{Proof: In Appendix 1}

This is a simple version of the well-known and controversial Miller-Modigliani Theorem in the theory of finance, which asserts that the value of the firm, in a given risk class, is independent of its capital structure (Debt-Equity Ratio). Here it says that a firm should be indifferent, given the indifference of the financier, between the FRS or VRS financing of its project if it is risk neutral.

Since we have assumed that a typical investor is risk averse it is not easy to determine the choice of contract, granting the fact that the expected payoff to the investors is identical across both contracts. In order to see which of the two contracts is preferred by a typical investor we need to look at the expected utility of the payoff at the point where the expected payoff is identical under two schemes. It is a well- known fact that a risk averse person would prefer less risky income stream among all those income streams having identical expected payoff. Thus our problem essentially reduces to determine the riskiness associated with payoffs across two schemes. This is accomplished below.

From (2) and (3) we have:

$$
\mathrm{Y}_{\mathrm{i}}^{\mathrm{F}}=\mathrm{z} \max \left(\mathrm{R}_{\mathrm{i}}-\mathrm{D}, 0\right) \text { and } \mathrm{Y}_{\mathrm{i}}^{\mathrm{V}}=\mathrm{a}\left(\mathrm{zR}_{\mathrm{i}}\right)
$$

At $a^{*}$ we also have:

$$
\mathrm{E}\left(\mathrm{Y}^{\mathrm{F}}\right)=\mathrm{E}\left(\mathrm{Y}^{\mathrm{V}}\right)
$$

Let $U_{i}$ be the utility function of the ith investor. We assume that $i u_{i}$ is concave and bounded function. Given (11) an investor prefers VRS if:

$$
\mathrm{E} \cdot \mathrm{U}\left(\mathrm{Y}_{\mathrm{i}}^{\mathrm{V}}\right)>\mathrm{E} \cdot \mathrm{U}\left(\mathrm{Y}^{\mathrm{F}}\right)
$$




\section{Fundamental Result}

Although we need only show that for a risk averse investor (12) is true we, how ever, will show a somewhat general result and the required result will follow as a corollary. In the next Proposition we will make use of the following definition:

\section{Definition}

For $0<\mathrm{a}<1$, an a-sharing rule is a function

$$
\text { S:IR---- IR }
$$

where IR is the real line, and such that

$$
\text { i) } 0 \leq \mathrm{S}(\mathrm{R}) \leq \mathrm{R}
$$

(13') ii) $\mathrm{ES}(\mathrm{R})=\mathrm{aE}(\mathrm{R})$

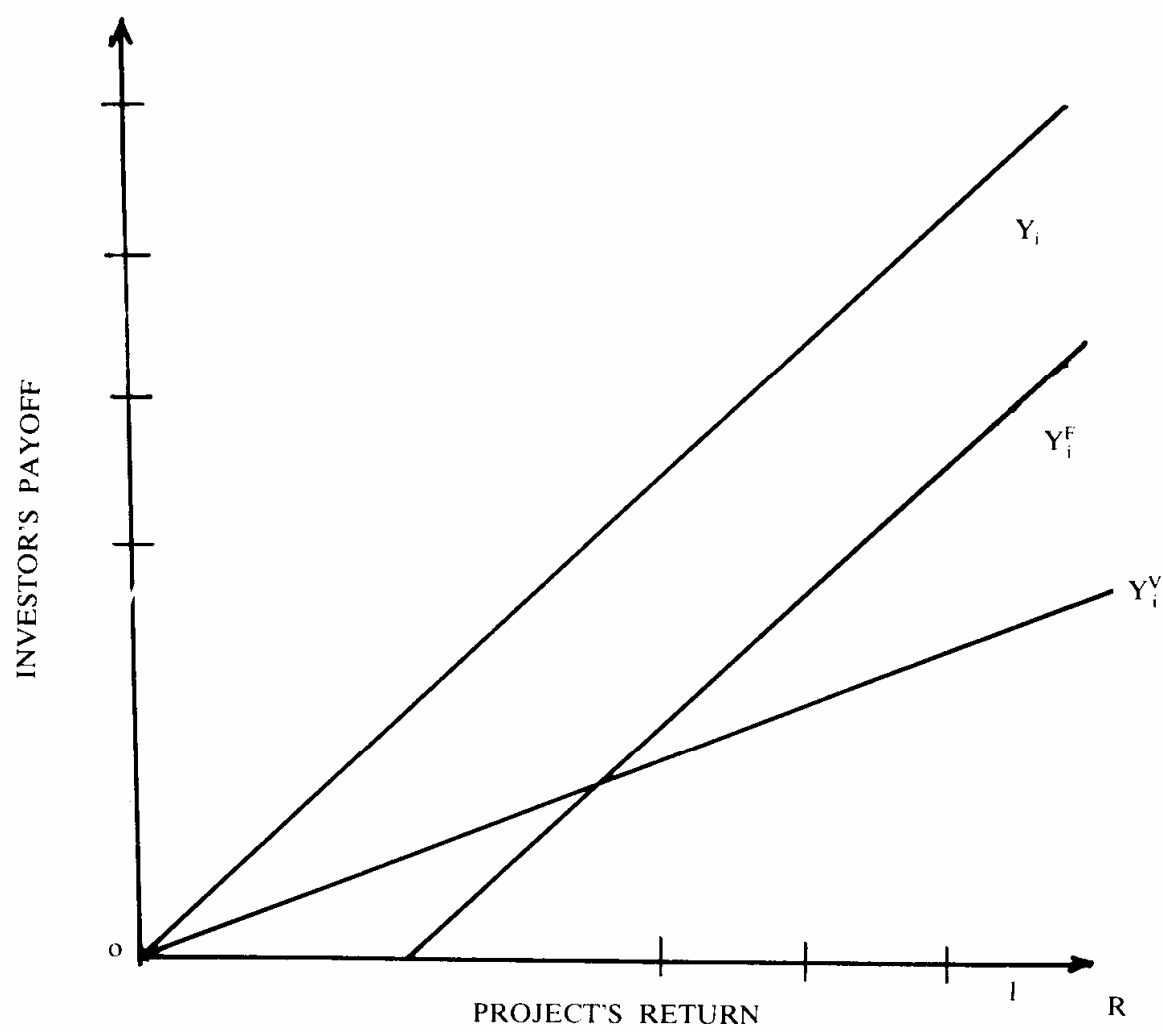

Fig. 1 


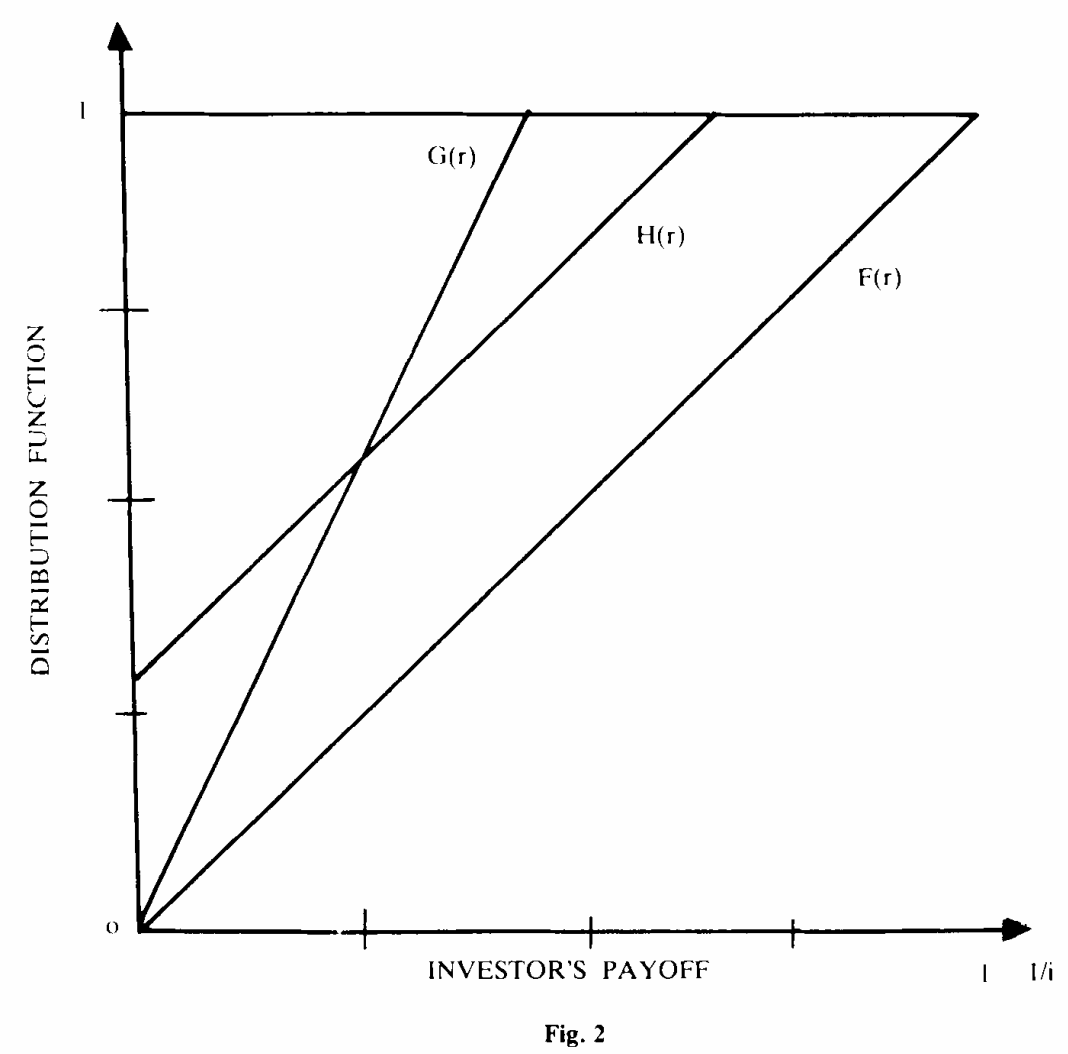

Proposition 2: Let

and

$$
\mathrm{S}^{*}(\mathrm{R})=\min (\mathrm{R}, \mathrm{D})
$$

$$
\mathrm{S}_{*}(\mathrm{R})=\max \left(\mathrm{R}, \mathrm{D}^{\prime}\right)
$$

Fix D and $D^{\prime}$ and choose a so that $S^{*}(R)$ and $S(R)$ are a-sharing rules. Then for any bounded and concave utility function $U$ and any a-sharing rule $S(R)$.

$$
\mathrm{E} \mathrm{U}\left[\mathrm{S}^{*}(\mathrm{R})\right] \geq \mathrm{E} \mathrm{U}[\mathrm{S}(\mathrm{R})] \geq \mathrm{E} \mathrm{U}\left[\mathrm{S}_{*}(\mathrm{R})\right]
$$

Proof: In Appendix 1

Proposition 2 identifies the most preferred and the least preferred a-sharing rules for a risk averse investor. But this also allows us to compare the VRS and FRS.

We would show that FRS is the least preferred scheme and as such VRS strictly dominates it. The following corollary establishes this fact: 
Corollary 2. A risk averse investor strictly prefers VRS over FRS.

Proof: In Appendix 1

Now we are in a position to state the most important result of this paper.

Theorem 1. Corresponding to each FRS there is a VRS which improves everyone's welfare.

Proof: In Appendix 1

We find figures 1 and 2 very helpful in understanding this theorem. In figure 1 we have shown the payoffs to the investor under VRS and FRS. The line Y**1 shows his payoff under VRS and the line $\mathrm{y}^{* *}$ shows his payoff under FRS. Assume that the random project return is uniformly distributed between $0 \& 1$. Then we can derive the distribution function for both $\mathrm{y}^{* *}$ and $\mathrm{y}^{* *}$. This is done in figure 2. The lines F(r), G(r) and $\mathrm{H}(\mathrm{r})$ give the distribution functions of $\mathrm{R}, \mathbf{y}^{* *}$ and $\mathrm{Y}^{* *}$ respectively. Note that $\mathrm{G}(\mathrm{r})$ and $\mathrm{H}(\mathrm{r})$ cross at some point, so we can fix the corresponding means at some values of a and $\mathrm{D}$. Thus $\mathrm{G}(\mathrm{r})$ and $\mathrm{H}(\mathrm{r})$ are the distribution functions with identical expected value. Now a risk averse individual will prefer that distribution which is less risky. It is clear from figure 2 that $G(r)$ is less risky since it is uniformly smooth whereas $H(r)$ takes jumps at the extreme values. The reason for the riskiness of $\mathrm{H}(\mathrm{r})$ lies in the fact that it has a positive probability mass at zero, an extreme value.

This theorem is the fundamental result of this paper. It suggests that under the assumptions (i-viii) the Pareto optimal contract is VRS. The intuitive reasoning behind the theorem lies in the way the risk is being spread across the two contracts. Given the fact that the choice of the contract depends on the preference of a typical investor, once the lender is indifferent, he prefers the one that is less risky. VRS has the characteristic of spreading risk more evenly than FRS and as such given risk averse investors VRS dominates FRS. This is the single most important gain of VRS and it has far-reaching implications for the stability of a financial system based on VRS.

Barring the transaction costs involved in the process of moving towards VRS arrangements it seems that the move is likely to be Pareto optimal.

This is a somewhat paradoxical result since it demonstrates inferiority of debt, the predominantly used form of financial contract. Note also that in this model full equity is the optimal choice and as such a combination of debt and equity is also dominated by an equity contract.

Since the above conclusion is central to our analysis in this paper it is essential that we must look very carefully at the underlying assumption. In the next section we critically examine each assumption and see how sensitive is our basic result to model specification. 


\section{A Critical Examination of the Assumptions}

The art of theorizing requires certain simplifying assumptions which might not be true. If they are not true and are made for mere simplification then the essential results of a theory should not be sensitive to the assumptions. If, however, a prediction of the theory crucially depends on a particular assumption then that assumption must be realistic or else justified on some other grounds.

In what follows we will discuss the role of each assumption in the above result and see how sensitive it is with respect to these assumptions.

The assumptions i, ii, iv, and identical distribution of project's return are made for convenience. So long as the law of large number holds for each of the several lenders we will get the dominance of the equity contract.

Given a fixed supply of loanable funds our model is basically a demand side model. We have not explained where this supply of funds comes from. We may interpret this as reflecting given saving decisions. But then one might well argue that these decisions would depend in the first place upon the type of contracts being offered by the financial institution. This is essentially the problem of determining the effect of introducing the system of profit sharing on the savings behavior of individuals.

If the financial institutions are engaged in offering only the equity financing, i.e. only the risky contracts, then one might suggest that total supply of loanable funds would be smaller than otherwise. The suspicion might arise from the idea that savings' incentives will be diluted if only the risky assets are offered. Therefore the results based on the assumption of a fixed supply of loanable funds cannot be relied upon.

There are two reasons for making such an assumption besides the argument that it is just the beginning effort of formally modeling the interest-free economy. First, though it may be true that the availability of risk free assets at the individual level induces more savings, it is not clear if aggregate savings in the economy are also affected by the nonavailability of such assets. That is, the aggregate savings function does not depend on the interest rate. Second, in many of the countries that we have in mind interest rate is controlled by the government and as such it plays little if any role in determining the level of savings. In fact the savings decisions are strictly based on the level of income. Most of the savings are either in the corporate sector or the public sector. Individual savings constitute a negligible part of the total savings. Therefore it seems natural to start off with the assumption of a fixed supply of loanable funds.

But it remained to be answered if, in the model where we do have a variable supply of loanable funds, the Pareto optimal contract will be different. It is not clear in which direction savings are going to change. This is a dynamic allocational problem. The introduction of Islamic schemes would make the future income more risky than what it is at any moment of time. Given this increased uncertainty, what changes in the consumption pattern would take place so that the expected utility over time is unchanged. Lyland (1969) has shown that if the utility function is characterized by decreasing risk aversion then the savings would go up. The idea is that with increased 
uncertainty and decreasing risk aversion, in order to maintain the same expected utility over time, an individual has to cut the present level of consumption.

Lyland's model does not answer the above question in sufficient generality. It however serves as a good counter example for those who would argue that the introduction of the new system would necessarily lead to a reduction in the supply of loanable funds. Thus we can safely conclude that the nature of the optimal contract would not necessarily change if we allow for the variable supply of loanable funds.

There is no problem in making an assumption like (iv), uncorrelated investment projects, in normal economic conditions. The only occasion where one can doubt the validity of such an assumption is the downswing of the business cycle when there is an economy-wide recession and declining profitability. But this in fact is a plus for the VRS because losses would spread throughout the credit market. It is ironic that VRS contracts would minimize such losses because there will be no bankcruptcies as would be triggered otherwise."

We now turn to the assumption regarding the separation of the project's performance and the financing decision. We have assumed that the nature of the contract does not influence the project's performance. More formally the production function is independent of the fact whether the funds are obtained through equity or debt.

In principle there can be no objection to such an assumption since the marginal product of a dollar of investment, ceteris-paribus, should be independent of whether the dollar is raised through debt or equity. But then this assumption has the implication of ruling out incentive effects associated with the ownership structure of the firm. There are two similar ways in which these incentive effects may arise.

Jensen and Meckling (1976) have argued that the behavior of the manager-owner depends crucially on the ownership structure of the firm. They have demonstrated that a manager behaves differently in case where he is not the sole owner of the firm than when he has the full ownership of the firm. The idea is that with the management of any firm the managers derive utility both from pecuniary returns (such as income from the project) and non-pecuniary returns or so-called perquisites (such as air conditioned office, attractive secretarial staff, purchase of inputs from friends, etc). There is always an optimal level of such perquisites consistent with the value maximization objective of the firm. When the firm is not managed by the owners then there is an incentive to carry the level of perquisites to a greater than optimal level, since the managers do not bear the entire cost of increased perquisites. Therefore the value of the firm will decline relative to what it would be if the firm is owned by the managers.

On the other hand a similar problem exists if the manager raises funds through debt. But here it is less severe since the manager, except in the bankrupt states, on the margin captures full benefits from the project.

\footnotetext{
${ }^{\star}$ For a detailed analysis of this claim see Khan (1985), Chapter 4.
} 
Another way of incorporating the incentive effects would be to allow investor's actions as an argument in the production function. Actions may be the efforts devoted by the investor. If the investor chooses an optimal level of effort then the supply of effort will be a function of the type of contract offered. Under the assumed conditions and disregarding the problem of monitoring the level of effort, the optimal contract is still VRS since it distributes the risk optimally. But the real problem is in fact that the level of effort is not observable. Under these circumstances the investor will not bring an optimal level of effort in the case of the VRS since he does not pay the full reduction in the value of the firm from a sub-optimal supply of effort. Thus the loss of utility to the investor resulting from lower value of the firm is smaller than the gain he receives from supplying a sub-optimal level of effort. But a debt contract will not produce similar effects since on the margin the above trade-off will be balanced in this contract if the project is successful.

Stiglitz (1974), Jensen and Meckling (1976) and Grossman and Hart (1982), have argued that there is in fact a trade-off between the benefits of risk spreading under equity and the incentive effects of debt, and in general there is an optimal level of debtequity ratio corresponding to maximizing behavior of the firm.

The above consideration falls into the general problem of 'moral hazard' which exists in the credit market. In part-II we discuss it in detail. We would see that the major reason for the preference of debt is the existence of a 'moral hazard' problem.

The assumption regarding risk aversion on the part of investors is very important for the main result of this paper. This is not an unrealistic assumption given the wide spread use of outside equity in the capital structure of many firms. Indeed the very existence of a stock market reflects society's desire for building up institutions for shifting risk to those most suited for this purpose, namely the stockholders.

The assumption of identical beliefs about the distribution of random return is a consequence of rational expectations on each side of the market. If this is not true then it can be shown that debt will be preferred even if the investors are risk averse. If an investor knows that the probability of default is very low then by getting funds through debt financing he can capture the upper tail of the return distribution, whereas in case of loss he loses nothing. This is also a kind of incentive problem, (see Stiglitz and Weiss, 1981). Here because of differential information structure investors have an incentive to undertake more risky projects than those which are in the interest of financier.

Since these instances are rare, i.e. full debt financing of the firm, it suggests that the assumption of rational expectation is a reasonable one.

Another important assumption of this paper is the costless observation of the project return by both the lender and borrower. In fact, this assumption and the separation assumption have close links since both avoid the potential problem of 'moral hazard' which would otherwise arise. 
Since in practice only the investor can costlessly observe the performance of the project, one should ask what is the implication of relaxing the assumption of costless observation by the lender. Thus one needs to look at the choice of financial contract when there is asymmetrical information in the credit market. Indeed it turns out that the predominant role played by debt in the real world can be explained on the grounds of asymmetrical information in the credit market. Debt has the characteristic of minimizing the informational requirement of a financial contract and as such given costly information collection, debt turns out to be the most attractive instrument of finance. We postpone further discussion of this problem until part-II where this is our main concern.

An assumption which is implicit in our formulation is the absence of any collateral requirement. In practice many debt schemes, specially in the agricultural sector in LDCs, require a collateral. On the other hand, as we saw in part-I, the Islamic scheme does not have any collateral requirement. Our results will be reinforced if we introduce it in the model.

Furthermore, it is clear that the requirement of a collateral restricts the entry of potential investors in the credit market. This is specially true of the agricultural sector where small farmers have virtually no access to the organized credit market because they can not bring the required collateral, (see Agarwal, 1982). As such the introduction of Islamic scheme would help to overcome this problem and consequently there may be a lot more investment activity in the economy.

Another important characteristic of Islamic financial scheme, that is not captured by our model, is reflected in the fact that such a financial system allows more risk taking in the economy. To see this assume that bankruptcy is costly. Now many of the investors who plan to undertake risky projects will be denied financing under a debt scheme, because in practice financial institutions operating with fixed liabilities are not allowed to choose a portfolio beyond a specified level of associated risk (e.g. restrictions imposed by the FDIC in USA). Whereas under an Islamic financial system no such restrictions are needed to impose since under such a system financial institutions will not issue fixed liabilities to their depositors. Accordingly, these institutions can finance more risky investment and thus assure a higher expected return in the economy. In fact there is a continuous decline in the volume of risky investment in Western Europe, indicating a greater desire for a financial system based on equity financing, (see Albach, 1981).

\section{PART II \\ Informational Asymmetry, Monitoring and Financial Contracts}

In the first part of this paper we have demonstrated the superiority of the Islamic financial scheme over the traditional scheme. We have also noted that this result is fairly robust in the sense that small deviations from the required conditions do not affect the dominance of Islamic scheme. But the internal consistency of our model requires that we should be able to explain the predominant role, in the real world, played by the Fixed Return Schemes. 
We will accomplish this end in the following analysis. We argue that the dominance of the FRS in the real world can be explained by the presence of informational asymmetry in the credit market.

Our problem in this part is in fact the well-known problem of explaining the existence of debt in the capital structure of a firm. Thus we will draw upon the existing theories of optimal capital structure in the theory of finance, but shall offer a new explanation for the preference of debt as an instrument of finance. In the first section we review the existing work in this area and indicate the place of the present effort. Section-II formally describes the problem considered and summarizes the results. Section-III develops the basic model. In Section-IV we again compare the two schemes under the new environment. Some concluding remarks are contained in the last section.

\section{Role of Debt in the Financial Structure of a Firm: A Survey}

In modern business organizations capital requirements are so immense that a single source of finance is insufficient. Therefore, we observe that large corporations in general have a diversified ownership structure. Thus it is not difficult to understand the diversified ownership structure. But what is somewhat difficult to understand is the fact that these organizations use different kinds of financing methods.

Why do we observe that firms obtain funds through different forms of financial instruments? In particular, why do firms use both debt and equity to finance their cap ital needs?

The traditional wisdom until the late fifties, was that the value of the firm can be increased by the judicious employment of debt in the capital structure of a firm.

The controversy over the role of debt in the financial structure of a firm started after the Miller-Modigliani theorem which states that the value of the firm is independent of its financing decisions. This is a paradoxical result, given the fact that most of the firms have some amount of debt and equity in their capital structure. Many authors have tried to place the role of debt in a firm's capital structure by relaxing the assumptions of the M-M theorem. In the beginning, efforts centered on the nobankruptcy and no-taxes assumptions. If the probability of bankruptcy is positive (and it is costly to go bankrupt) then firms and individual borrowers cannot have equal access to credit markets. Firms can issue debt at a lower rate than individuals and this raises the value of the firm. On the other hand if debt payments are tax deductible then again, debt would be cheaper relative to equity.

A different line of attack is taken by Stiglitz (1974), Jensen and Meckling (1976), and Grossman and Hart (1982). They have relaxed a somewhat different assumption of the M-M theorem: that the firm's production function is independent of its financial structure. Stiglitz and Jensen and Meckling consider the situation of an investor who has access to an investment project but does not have sufficient funds to finance it. If the investor raises funds by issuing equity, then as he will have a less than 100 percent interest in the project, he will not manage it as carefully as he would, had he been a full owner. If, on the other hand, the investor issues debt then his incentive to work will 
reduce much less since, except in bankrupt states, he gets full benefits of any increase in profits. Thus to Stiglitz and Jensen and Meckling, debt is a way of permitting expansion without sacrificing incentives. The trade-off for the investor is between equity, which permits the sharing of risks, and issuing debt, which leads to a high market value of the project through the incentive effect. Grossman and Hart (1982) have utilized the same idea except for the fact that management/investor has zero shareholding in the firm and as such bankruptcy penalties have a significant effect on their model.

Ross $(1977,1978)$ on the other hand has given a different explanation using the signaling model. For Ross in a world where there are firms of different quality debt is a signal of the quality of the firm. In equilibrium the value of the firm is positively correlated with the debt-equity ratio. The idea is that, given costly bankruptcy it is not in the interest of low quality firms to have more debt in their capital structure.

Our model is different from the above models. Bankruptcy is not costly in our model, neither is there differential tax treatment across different financial instruments. We have assumed that the production function is independent of the financial structure and that there are no quality differences across firms. In other words our model does not rely on (i) imperfections in the capital market, (ii) differential tax treatment, (iii) incentive effect or signaling potential of debt. Rather we find a role for debt on the ground that it minimizes the information requirement of a financial contract, when the performance of the project is not observable by the financial institution.

Since our motivation for the present analysis is to see the implications of prohibiting debt from the economy, we will argue later in this paper that the success of this proposal depends on the availability of information in the economy. The implementation of a profit sharing system as the basis for financial intermediation will force financial institution to invest additional resources in information collecting activities. These information costs are a deadweight loss to the society, and as such the introduction of the new system may lead to a Pareto inferior outcome.

\section{Basic Problem and Results}

In this section we informally describe the problem considered in this part and summarize the results.

Assume that there is a financial institution extending loans to an investor. Also, as in part-i the supply of loanable funds is fixed. Moreover, both the lender and the financial institution have identical beliefs about the probability distribution of the return from the project where funds are invested. Part I.

The payoffs to the lender and investor under FRS and VRS are the same as in

It was demonstrated in Part-I that in the absence of any kind of informational problem, the Pareto optimal contract is the VRS. Our objective now is to show that the predominant role played by the fixed return contracts is the result of informational asymmetry. 
The basic problem considered in this paper is the following:

When the lender extends a loan to an investor, then the investor observes the return of the project without incurring any costs, while the lender cannot observe the return. If it is prohibitively expensive for the lender to observe the return then the market for financial loans will not exist. There is, in the case of the lender's inability to observe the project's performance, a strong incentive problem: investors will tend to underreport the project's performance. Thus the best strategy for the lender is not to extend any loan.

Although the problem of informational asymmetry is a severe one it does not necessarily lead to market failure for there are things like collateral, auditing, participation in the board of directors of the firm, and other forms of monitoring which to a large extent resolve the problem of informational asymmetry. Furthermore, in a multi period framework the fear of losing reputation in the credit market could be a strong incentive for investors to refrain from misrepresentation. Indeed, the types of contracts offered in the credit market resolve the incentive problem.*

Therefore in the present analysis we allow for the possibility of monitoring the performance of the project by the lender at some expense. Later in this paper we will reflect on the practical feasibility of monitoring investment projects by the financial institutions.

Given the possibility of monitoring, a few questions remain. What types of monitoring technologies are available and what are the characteristics of an optimal monitoring technology? How does the monitoring technology differ across two contracts? Given optimal monitoring technologies across two contracts is there some way to choose one of these? Similarly we look at the behavior of an investor to find out his optimal response for underreporting the project return.

We summarize our results below:

(i) The optimal monitoring technology is a randomized strategy which gives the probability of monitoring a reported return. It allows investors to underreport only to the extent that the gain from monitoring is equal to the cost of monitoring. The probability of monitoring goes down for a given reported return the higher is the cost of monitoring.

(ii) Given a uniform distribution of returns the expected monitoring costs are lower under the FRS. Since these costs are a deadweight loss to the society, this loss is greater under the VRS. This result in general depends on the density of returns. For the densities having smaller mass below D, the FRS dominates, while for others the result would change.

\footnotetext{
* See the literature on the principal/agent problem (2), (7), (10) and (12). The primary problem is tore solve
} the conflicting interests of the principal/agent through the nature of the contract. 
(iii) The choice of a particular contract crucially depends on the attitude of the investor towards risk. There is no straightforward dominance of any scheme if investors are risk averse. Though FRS minimizes the monitoring costs it does not spread the risk optimally. Thus for a sufficiently high degree of risk aversion VRS may dominate FRS.

(iv) The above results can be used to seek an explanation of why the M-M theorem does not hold in a world of informational asymmetry. An expanding firm looking for outside sources of finance may find it more attractive to borrow funds on the basis of the FRS rather than issue equity.

\section{The Model}

Suppose both the lender and the investor believe that $\mathrm{R}$ is uniformly distributed in $(\mathrm{d}, 1)$, where $\mathrm{d}$ is some positive constant which is different across two schemes. ${ }^{*}$ The assumption of uniform distribution is made for convenience. Though some of the results do depend on this specification, the essential features of the solution are independent.

Let $\mathrm{G}$ be the space of all possible ways of underreporting the return. The investor picks $\mathrm{G}$ which translates $\mathrm{R}$ into some reported return, i.e.

$$
\mathrm{g}:(\mathrm{d}, 1) \rightarrow(\mathrm{d}, \mathrm{l})
$$

Let $\mathrm{H}$ be the space of all possible ways of monitoring the reported return $\mathrm{g}(\mathrm{r})$. In general $\mathrm{H}$ is a very large space and includes things like collateral, auditing, participation in the management, etc. But we restrict $\mathrm{H}$ to include only the ways in which the lender makes a decision whether or not to go for auditing. That is, after looking at the reported return the lender may decide whether it is acceptable or subject it to auditing. In case the lender decides to have it audited he can look at the accounts of the firm or ask the firm to verify its accounts by independent auditors. We assume that monitoring (auditing) is perfect in the sense that once the lender decides to monitor he knows for sure what the true return was. Furthermore there is no separate problem of recovery. Thus the lender picks $h \in H$ that describes the monitoring possibilities. Note that $h=0$ if he decides not to monitor a given reported return, whereas $h=1$ means he surely monitors. If $h$ takes a value in the interval $(0,1)$ then we interpret it as giving the probability of monitoring a given reported return. In other words the lender may choose either a pure strategy $(\mathrm{h}=$ 0 , or $h=1$ ) or a randomized strategy. The same is true of the investor.

Thus:

$$
\mathrm{h}:(\mathrm{d}, \mathrm{l}) \rightarrow(0,1)
$$

The optimal $\mathrm{h}$ and $\mathrm{g}$ will have different characteristics. They will depend on the cost of monitoring and the optimal $h$, respectively.

Let $\mathrm{b}$ be some fixed cost of monitoring. The problem of the investor is to choose $\mathrm{g}(\mathrm{r}) \in \mathrm{G}$ for a given $\mathrm{h}(\mathrm{g} ; \mathrm{b})$ to maximize

\footnotetext{
* This assumption is made to fix a technical problem that arises in the inversion of the investor's under
} reporting function. 


$$
\max \operatorname{EU}(\mathrm{Y})=\mathrm{EU}(\mathrm{Y}(\mathrm{r}, \mathrm{g}, \mathrm{h}(\mathrm{g}, \mathrm{b})))
$$

where $r$ is the observed value of $R$ and $Y($.$) is the payoff to the investor. U$ is the utility function. The solution of (3) gives the optimal underreporting strategy of the investor which is the mapping:

$$
\mathrm{g}^{*}(\mathrm{r}):(\mathrm{d}, \mathrm{l}) \mathrm{XH} \rightarrow(\mathrm{d}, 1)
$$

On the other hand, the lender's problem is to choose $\mathrm{h} \in \mathrm{H}$ for a given $\mathrm{g}(\mathrm{r})$, to maximize

$$
\max \operatorname{EU}(\mathrm{P})=\mathrm{EU}(\mathrm{P}(\mathrm{h}(\mathrm{g}, \mathrm{b}), \mathrm{g}(\mathrm{r})))
$$

The solution to (5) gives the optimal h, which is the mapping:

$$
\mathrm{h}^{*}:(\mathrm{d}, 1) \mathrm{XG} \rightarrow(0,1)
$$

Equations (3)-(6) define the game whose solution is what we are looking for. The solution (Nash Equilibrium) of the game is the pair $\left(\mathrm{g}^{*}, \mathrm{~h}^{*}\right)$ satisfying:

$$
\begin{gathered}
\operatorname{EU}\left(\mathrm{Y}\left(\mathrm{g}^{*}, \mathrm{~h}^{*}\right)\right) \geq \mathrm{EU}\left(\mathrm{Y}\left(\mathrm{g}, \mathrm{h}^{*}\right)\right) \text { for all } \mathrm{g} \in \mathrm{G} \\
\mathrm{EU}\left(\mathrm{P}\left(\mathrm{g}^{*}, \mathrm{~h}^{*}\right)\right) \geq \mathrm{EU}\left(\mathrm{P}\left(\mathrm{g}^{*}, \mathrm{~h}\right)\right) \text { for all } \mathrm{h} \in \mathrm{H}
\end{gathered}
$$

In what follows we will solve the game explicitly across both of the contracts.

\section{Solution under VRS}

In this contract the investor observing $r$, reports $\mathrm{g}(\mathrm{r})$ out of which $(1, \mathrm{a}) \mathrm{g}(\mathrm{r})$ is given to the lender. If he is monitored then he looses $(1-\mathrm{a})(\mathrm{r}-\mathrm{g}(\mathrm{r}))$ thus his expected payoff is given as:

$$
\mathrm{Y}^{\mathrm{V}}=\mathrm{r}-(1-\mathrm{a}) \mathrm{g}(\mathrm{r})-\mathrm{h}(\mathrm{g})(1-\mathrm{a})(\mathrm{r}-\mathrm{g}(\mathrm{r}))
$$

Although the investor is assumed to be risk averse for a moment we ignore the utility function and maximize (8) over $\mathrm{g}(\mathrm{r})$. The solution of (8) is given by:

$$
\mathrm{g}^{*}(\mathrm{r})=\mathrm{r}+(1-\mathrm{h}(\mathrm{g})) / \mathrm{h}^{\prime}(\mathrm{g})
$$

where $h^{\prime}(g(r))=d h(g(r)) / d g(r)$ indicates the change in the probability of monitoring when the investor reports more. Note that we should expect $h^{\prime}(g)<0$. If the probability of monitoring is unaffected by how much the investor reports then the investor would report the minimum possible return. In fact this is the dominant strategy for the investor. Since there is no explicit penalty for underreporting, an investor loses nothing (in a single period model) by taking a chance for underreporting to the fullest possible extent. 
Therefore a monitoring technology which induces investors to report more should have an inverse relationship with the reported return. As such there will be an implicit penalty in the form of changing probability of monitoring. Thus the investor faces a trade-off between the loss from reporting more and a decrease in the chances of being monitored, when he reports more. The first order condition which gives (9) shows the point where the two things are balanced.

The payoff to the lender under the VRS is given by:

$$
E\left(P^{V}\right)=\int_{d}^{1}[(i-a) g(r)+h(g, b)(1-a)(r-g(r)-b)] m d r
$$

where $\mathrm{m}=1 /(1-\mathrm{d})$

Note that $\mathrm{r}$ cannot be an argument in his maximizing problem since he does not observe r. However we can still maximize (10) by maximizing only the integrand for a given $\mathrm{g}(\mathrm{r})$.

We have assumed that monitoring is perfect in the sense that whenever the lender monitors he knows for sure what the true value of $r$ was. In particular this assumption has the implication that in equilibrium the lender can figure out the entire $\mathrm{g}(\mathrm{r},$. mapping. But this requires that $\mathrm{g}(\mathrm{r}$, .) should be invertible for $\mathrm{r}$. For if this is not possible then the lender would never know the feasibility of monitoring. As such he would never engage in the contract.

Let $\mathrm{C}$ be the costs of monitoring under the VRS then:

$$
\mathrm{E}\left(\mathrm{C}^{\mathrm{V}}\right)=\int_{\mathrm{g}(\mathrm{R})} \mathrm{bh}(\mathrm{g}(\mathrm{r})) \mathrm{dg}(\mathrm{r})
$$

is the expected monitoring cost under the VRS.

Now we have the following proposition giving the solution pair for the VRS:

Proposition - 1. Let $\left(\mathrm{Y}^{\mathrm{v}}, \mathrm{P}^{\mathrm{v}}, \mathrm{g}, \mathrm{h}, \mathrm{C}^{\mathrm{v}}\right)$ be the game defined above.

Then the Nash solution is given by the pair:

$$
\left(g^{*}, h^{*}\right)=(r-b / 1-a, 1-\exp -[(1-a)(1-g(r)-b / b]) \text { and }
$$

minimizes the expected cost of monitoring.

Proof: In Appendix - 2

The optimal strategy of the investor is a pure one. This makes sense since the lender, after observing $\mathrm{r}$ can report anything in the interval $(0,1)$ which is a convex and compact set. Given the optimal strategy of the lender, the best he can do is to under 
report only to the extent that the lender is indifferent between monitoring and not monitoring. This can be seen by rewriting $\mathrm{g}^{*}(\mathrm{r})$ as:

$$
(1-a)\left(r-g^{*}(r)\right)=b
$$

The left hand side is the gain from monitoring to the lender while $\mathrm{b}$ is the cost of monitoring.

On the other hand the lender's optimal strategy is randomized. To see that this makes sense, assume that the lender is restricted to a pure strategy. His optimal strategy would then be to monitor all the time, for if this were not true then the investor would underreport to the fullest extent. This would mean that the return to the lender would be minimum. Therefore he has to monitor all the time. But even if he monitors all the time the optimal strategy of the investor is still reporting the minimum possible return. Indeed this is the dominant strategy of the investor. Furthermore under this equilibrium full monitoring costs have to be incurred. There is also another problem associated with this equilibrium and that is the instability of this equilibrium. The instability arises from the fact that in the presence of a small penalty there is no Nash equilibrium. Also, if one investor tells the truth this would render the lender's strategy sub-optimal.

Thus we have demonstrated that monitoring or no monitoring cannot be optimal. Randomization of the lender's strategy also induces the investor not to underreport outright. Thus as we expected h' $<0$ This, in fact, acts like an implicit penalty which provides investors with an incentive to refrain from outright misrepresentation.

Another important characteristic of this monitoring technology is its relation to the cost of monitoring. As one should expect, the technology is an inverse function of the cost of monitoring. For a given level of reported return the probability of monitoring decreases as the cost of monitoring increases. Note that for a sufficiently high value of $b$ no monitoring takes place.

\section{Solution under FRS}

In this contract, the investor observing $\mathrm{r}$ reports $\mathrm{g}(\mathrm{r})$ that is given to the lender. Note that here there is no need for reporting $g(r)>D$. At most $g(r)=D$. Thus the investor's payoff is given by:

$$
Y^{F}=r-g(r)-h(g(r))(\min (r, D)-g(r))
$$

maximizing (14) over $\mathrm{g}(\mathrm{r})$ gives:

$$
\mathrm{g}^{*}(\mathrm{r})=\min (\mathrm{r}, \mathrm{D})+(\mathrm{l}-\mathrm{h}(\mathrm{g}(\mathrm{r}))) / \mathrm{h}^{\prime}
$$

The payoff to the lender on the other hand is given by:

$$
\mathrm{E}\left(\mathrm{P}^{\mathrm{F}}\right)=\int^{1}[\mathrm{~g}(\mathrm{r})+\mathrm{h}(\mathrm{g}(\mathrm{r}))(\min (\mathrm{r}, \mathrm{D})-\mathrm{g}(\mathrm{r})-\mathrm{b})] \cdot \operatorname{mdr}
$$

maximizing along the same line as in case of the VRS we can get the optimal h. 
Let $\mathrm{C}^{\mathrm{F}}$ be the cost of monitoring under the FRS, then:

$$
\mathrm{E}\left(\mathrm{C}^{\mathrm{F}}\right)=\mathrm{bh}(\mathrm{g}(\mathrm{r})) \mathrm{dg}(\mathrm{r})
$$

gives the expected monitoring cost under the FRS.

We now have the following proposition:

Proposition - 2: Let $\left(\mathrm{Y}^{\mathrm{F}}, \mathrm{P}^{\mathrm{F}}, \mathrm{g}, \mathrm{h}, \mathrm{C}^{\mathrm{F}}\right)$ be the game defined above for the FRS. Then the Nash solution is given by the pair:

$$
\left(\mathrm{g}^{*}, \mathrm{~h}^{*}\right)=(\min (\mathrm{r}, \mathrm{D})-\mathrm{b} ; 1-\exp -[(\mathrm{D}-\mathrm{b}-\mathrm{g}(\mathrm{r})])
$$

and minimizes the expected cost of monitoring.

Proof: In Appendix - 2

The optimal strategies of the lender and the investor are the same except for the parametric differences across the two contracts. Here the extent of underreporting is $b$ rather than $b / 1$ - a and the lender does not monitor above D - b. The optimal payoffs corresponding to (18) and the expected monitoring costs are given in Appendix - 2.

In the next section, we develop a criterion which allows us to compare the two schemes and which also helps in the selection of a contract.

\section{Comparison between Two Schemes}

In the preceding section we have demonstrated that in the presence of informational asymmetry monitoring costs exist across both of the contracts. Thus the choice of the contract should somehow take into account the existence of these costs. In what follows, we will argue that the size of these costs indeed determines the choice of the contract.

Given the fact that there is just one financial institution, it seems natural to assume that it only cares for the expected return across the two schemes. Even if it is risk averse an appeal to the law of large numbers, as in Part-I, would allow the lender to look only at the expected return. Since the VRS is a continuous scheme in the sense that for every $\mathrm{D}$ there is an a such that the lender's expected payoff across the two contracts is identical, the choice of the contract again hinges upon the preference of the investor. Thus we first look at the conditions under which the lender is indifferent across the two contracts. This can be accomplished in two different ways:

(i) The lender can equalize the payoffs under the two schemes with the information costs. This means that for every D we need to find an a such that:

$$
\mathrm{E}\left(\mathrm{P}^{\mathrm{F}}\right)=\mathrm{E}\left(\mathrm{P}^{\mathrm{v}}\right)
$$

Then at this point we look at the behavior of the investor to see which contract will be chosen. 
(ii) The lender can equalize the payoffs under the two schemes as well as across the two situations (with or without information costs). This means that he passes on the monitoring costs to the investor in the form of a lower 'a' and a higher 'D'. Then again at this point we can look at the preference of the investor.

For its computational ease we take the second approach. The following proposition determines the size of the monitoring costs across the two contracts.

Proposition - 3. Let R be a uniformly distributed random return.

Choose a and D so that

$$
\mathrm{E}\left(\mathrm{P}^{\mathrm{F}}\right)=\mathrm{E}\left(\mathrm{P}^{\mathrm{V}}\right)
$$

then the expected monitoring costs under the FRS are smaller than under VRS.

Proof: In Appendix - 2

The second condition in the proposition gives a point of reference by establishing a link between a and $\mathrm{D}$, the parameters of the two contracts.

This is intuitively the best result of this paper, and also central to our claim that the predominant role played by the fixed rate transactions in the real world is the result of informational asymmetry in the credit market.

Under the FRS type of transactions since the lender requires a fixed return, only a reported return below that fixed return is suspicious. As such, monitoring will not take place above this return. On the other hand, under the VRS the upper limit on monitoring is much higher. This makes monitoring more frequent under VRS.

There is another interesting difference across the two schemes. Under FRS, below D whatever is discovered goes to the lender, whereas under the VRS only (1 - a), of discovery goes to the lender. Thus for small values of return there will be little inclination for monitoring under the VRS. But this last fact is disguised by the assumption of uniform distribution. As such, we get a straightforward dominance of the VRS on account of minimizing expected monitoring costs.

In general the result depends on the probability mass of $\mathrm{R}$ below $\mathrm{D}$. For the densities having smaller mass below $\mathrm{D}$ the above result holds, for others it may reverse.

Assuming that the lender will behave competitively, he will pass on these costs to the investors in the form of higher $\mathrm{D}$ and lower a. This fact is established in the following lemma:

Lemma - 1. Let $(1-a),\left(1-a^{\prime}\right), D$, and D' denote the share and the fixed return of the lender without and with information costs respectively. Then if the lender equalizes his return across the two schemes under both situations, then:

$$
\begin{aligned}
a^{\prime} & <a \\
D^{\prime} & >D
\end{aligned}
$$


Proof: In Appendix - 2

Now we are in a position to state the fundamental result of this part.

Proposition - 4. The choice of a financial contract depends on investor's attitude toward risk. For a sufficiently low degree of risk aversion the FRS dominates over the VRS.

Proof: In Appendix - 2

Thus we have shown that one of the most important reasons for the preference of the FRS type of financial contracts is the result of informational asymmetry in the financial markets. A debt contract minimizes the information requirement associated with any financial contract. Given that information collection is costly this contract appears most attractive.

In the next section we will comment on the feasibility of monitoring under the Islamic financial system.

\section{Monitoring under the New Financial System}

The analyses in the preceding section are based on the assumption that the lender is in a position to monitor the performance of the project at some expense.

The results point to the existence of higher monitoring costs under the Islamic scheme. In fact we have argued that observed dominance of debt schemes is the result of its cost minimizing characteristics. Debt contracts require least organizational costs and hence are popular throughout the world. The additional costs under the new system primarily stem from the fact that being a partner of the firm requires more active vigilance of the firm's activities in order to protect one's self-interests. A creditor of the firm does not have equivalent stakes in the firm.

A natural question that arises is to see whether the resulting costs are prohibitive enough to cast doubt over the viability of the new system. There is a number of considerations which point to the fact that the additional costs will not be prohibitive. First, the problem of 'moral-hazard' we have described is not unique to the financial sector. In fact it largely exists in insurance business. But we know that insurance industry has evolved over a long period of time efficient methods to combat the problem. The solution has been primarily in the form of designing 'incentive compatible' policies which either eliminate or minimize the incentive for misrepresentation by the insured. The ever increasing coverage provided by the industry is a reflection of the fact that it has steadily found ways to provide insurance in areas where because of lack of information it could not have provided earlier.

Second, the information collection industries are decreasing cost industries, since this activity requires fixed costs of considerable size. Therefore such an activity can be performed efficiently by a single firm in the industry. if there is a large financial institution as we have assumed in our model then the resulting costs can be minimized. 
Third, in modern corporations a large amount of equity is owned by individual shareholders. Individual holdings are, however, small relative to the total assets of the corporation. This generates an externality: a shareholder acting individually can not monitor the actions of the managers who thus acquire a great deal of decision making power which may not be in the best interest of all owners. On the other hand when these corporations issue debt, specially to banks, then banks closely watch the performance of managers. Since a bank's lending is a sizeable proportion of total capital, in order to attract a bank's financing managers agree to refrain from certain actions which they would normally take*. Therefore banks to a large extent are able to internalize this externality. The new system can hope to derive one of its most important benefits from the internalization of this externality. When a financial institution holds a large part of a firm's equity one should expect that the lender would be more cautious in monitoring the firm's activities than when the lender issues debt. Given this increased participation of the financier, one can also hope for a better overall performance by those managers who have little, if any, self-interest in the corporation.

Fourth, there are systems more complex than the system of profit and loss sharing which are currently in operation and have an excellent performance record. For example, all the taxation systems which collect direct taxes are in fact a kind of PLS system. In some developed countries, such as USA, the direct tax collections are as high as 80 percent of total collections. The system of income tax can be thought of as a system of revenue-sharing between government and individuals, because a certain percentage of unknown income is taken as tax. Each year millions of tax payers report their income and pay taxes. There is a huge monitoring expenditure incurred by the state to correctly assess the incomes of the individuals. The existence of such a system is the required proof of its viability.

Finally, one should also allow for those benefits which the new system will bring about. These are, greater risk-spreading and more risk-taking which have been pointed earlier in the paper. Also, there is the advantage of greater stability in financial intermediation.**

In the light of above discussion we may conclude that the monitoring costs will not be prohibitive for the new system. Of course there is a painful transitionary period which the new system has to face. Much depends on the ability of financial institutions to develop effective monitoring methods. This cannot be done in a short period of time. A gradually evolving change is the right course of action.

* See Jensen and Meckling (1976)

** For detailed discussion see Khan (1955) and, Mohsin S. Khan, Islamic Interest-Free Banking: A Theoretical Analysis, IMF, Researeh Department DM 185/54, September 1985. 


\section{Conclusions}

In this paper we have analyzed the problem of prohibiting Riba from the Our analysis has been partial in the sense that only the demand side has been considered. Under a given set of assumptions it has been shown, in Part-I that the Islamic scheme is superior to the traditional scheme. The risk-spreading characteristic of the Islamic scheme is the driving force behind this result.

In Part-II we relaxed a major assumption of Part-I, i.e. the assumption of symmetric information between the lender and the investor. Under the new scenario the debt contract emerges as the most efficient contract since it minimizes the monitoring costs which result because of asymmetric information.

The major result of this paper is that the Islamic financial system is superior to a non-Islamic system if there is no dishonesty. To us, as to many others as well, this is not a very surprising result. But at the same time the requirement of honesty, for the success of the Islamic system, is very stringent. Perhaps the deepest question raised by this research is whether the efforts of Islamization, specially in one direction (economic system), would be successful or not. The answer in the very short run seems to be negative.

But we strongly resent the implication that these efforts should be abandoned. Certainly society will have to pay a very high price for Islamization, and indeed the benefits of Islam, as history shows come after sacrifices are made. One should also allow for the benefits society would supposedly derive from the preservation of a spiritual value. Thus it is the job of policy makers to weigh the benefit/cost of this policy change.

It is very important that other institutions based on non-Islamic principles should also be changed. This is a long-run menu and one should not expect a miracle changing everything in the desired direction overnight. Thus in the short run costly partial moves can be sustained in the hope of dynamic gains from the changing attitudes in the society over a longer period of time.

The problem of dishonesty is, to a large extent, overemphasized in our model which is a single period model. In our opinion dishonesty is a function of the incentive structures afforded by the society, and also in a value-oriented society, of the fear of God. The second factor is by and large exogenous and can only be changed in the very long run. We believe that the short run costs can be minimized by devising incentive structures that ensure the honesty of agents endogenously.

The credit market is the kind of market where agents transact repeatedly. It is possible, therefore, to devise financial schemes embodying incentive mechanisms, so that agents reveal the truth even if they are not sufficiently afraid of God. This is the area of research where Islamic economists will have to devote most of their energies for the successful replacement of the present financial system. 


\section{References}

Agarwal, P. (1982) "Financial Markets in Developing Countries: A new Analysis with Transaction Costs", Ph.D Thesis (Chapter 2), Stanford University, Economics Department.

Albach, M. (1981) "Risky Capital, Business Investment and Economies Cooperation", Paper presented at the International Symposium on "Islamic Banks and Strategies of Economic Cooperation", in Baden-Baden, West Germany.

Grossman, S. and Hart, O. (1982) "Corporate Financial Structure and Managerial Incentive", in John J. McCall (Ed.), The Economics of Information and Uncertainty, NBER Conference Report No. 32.

Harris, M. and Raviv, A. (1979) "Optimal Incentive Contracts with Imperfect Information", JET, 20.

Holmstrom, B. (1979) "Moral Hazard and Observability". BJE, 10, (Spring).

Jensen, M. and Meckling, W. (1976) "Theory of the Firm: Managerial Behavior, Agency Costs and Ownership Structure", Journal of financial Economics, 3 (October): 305-360.

Leyland, H. (1969) "Savings and Uncertainty: The Precautionary Demand for Savings", QJE, 82: 465- 473.

Khan, Waqar M. (1985) Towards an Interest-Free Islamic Economic System: A Theoretical Analysis of Prohibiting Debt Financing, Leicester: The Islamic Foundation.

Miller, M. and Modigliani, F. (1958) "The Cost of Capital Corporation Finance, and Theory of Investment", $A E R$, 48: 423-443.

Ross, S. (1977) "Economic Theory of Agency: The Principal's Problem", AER, 63 (1973):134-139. (1977) "The Determination of Financial Structure: The Incentive Signaling Approach", BJE, 8, No.1:32-40.

(1978) "Some notes on Financial Incentive Signaling Models, Activity Choice, and Risk Preference", Journal of Finance, 33, No. 33: 777-791.

Rothschild, M. and Stiglitz, J. (1970) "Increasing Risk - I", JET, 20:315-329.

Stiglitz, J. (1972) "Some Aspects of Pure Theory of Corporate Finance, Bankruptcies and Takeovers", BJE, 3, No. 2: 458-482.

(1974) "Incentives and Risk-Sharing in Share Cropping", Review of Economic Studies, 41(2), No.126: 219-257.

and Weise (1981) "Credit Rationing in Markets with Imperfect Information", AER, June. 


\section{Appendix - 1}

Lemma - 1: Let $\mathrm{P}_{\mathrm{z}}$ be a sequence of identically and independently distributed random variables with mean $\operatorname{LE}\left(\mathrm{P}_{\mathrm{z}}\right)$ and variance $\mathrm{zLvar}\left(\mathrm{P}_{\mathrm{z}}\right)$ then

$$
\mathrm{P}_{\mathrm{z}} \rightarrow \mathrm{LE}\left(\mathrm{P}_{\mathrm{z}}\right) \text { as } \mathrm{z} \rightarrow 0
$$

Proof: For fixed e positive, by Chebysheve's inequality we have

$$
\operatorname{Pr}\left[\left|\mathrm{P}_{z}-\mathrm{LE}\left(\mathrm{P}_{\mathrm{z}}\right)\right|>\mathrm{e}\right]<\left(1 / \mathrm{e}^{2}\right)\left[\operatorname{var}\left(\mathrm{P}_{\mathrm{z}}\right)\right]=\left(1 / \mathrm{e}^{2}\right) \mathrm{zL} \operatorname{var}\left(\mathrm{P}_{\mathrm{z} i}\right)
$$

which goes to zero as z goes to zero.

Lemma - 2: Let $\mathrm{P}_{\mathrm{z}}$ be a sequence of I.I.D. random variables which converges to $\mathrm{E}\left(\mathrm{P}_{\mathrm{z}}\right)$ in probability. If $\mathrm{U}_{\mathrm{b}}$ is a continuous function then

$$
\mathrm{U}_{\mathrm{b}}\left(\mathrm{P}_{\mathrm{z}}\right) \rightarrow \mathrm{U}_{\mathrm{b}}\left(\mathrm{E}(\mathrm{P}) \text { as } \mathrm{z} \rightarrow 0 \text {, where } \mathrm{P}=\mathrm{E}\left(\mathrm{P}_{\mathrm{z}}\right)\right.
$$

Proof: Fix $\eta$, a positive number. Let $\mathrm{I}$ be an arbitrary interval such that

$$
\operatorname{Pr}[\mathrm{P} \in \mathrm{I}]=1-\eta / 2
$$

Now since $\mathrm{P}_{\mathrm{z}}$ converges to $\mathrm{P}$ in probability, there exists an $\mathrm{z}_{\mathrm{o}}$ such that for all $\mathrm{z}<\mathrm{z}_{\mathrm{o}}$ we have

$$
\operatorname{Pr}\left[\left|\mathrm{P}_{\mathrm{z}}-\mathrm{P}\right|<\delta\right]=1-\eta / 2 \quad \text { for all } \mathrm{P} \in \mathrm{I} \text { and any }
$$

positive $\delta$. Since $\mathrm{U}_{\mathrm{b}}$ is continuous we have for any e positive

$$
\begin{gathered}
\left|\mathrm{U}_{\mathrm{b}}\left(\mathrm{P}_{\mathrm{z}}\right)-\mathrm{U}_{\mathrm{b}}(\mathrm{P})\right|<\mathrm{e} \text { if }\left|\mathrm{P}_{\mathrm{z}}-\mathrm{P}\right|<\delta \\
\text { hence } \begin{aligned}
\operatorname{Pr}\left[\mathrm{U}_{\mathrm{b}}\left(\mathrm{P}_{2}\right)-\mathrm{U}_{\mathrm{b}}(\mathrm{P}) \mid<\mathrm{e}\right] & >\operatorname{Pr}\left[\mathrm{P}_{\mathrm{z}}-\mathrm{P} \mid<\delta, \mathrm{P} \in \mathrm{I}\right]=\operatorname{Pr}\left[\mathrm{P}_{\mathrm{z}}-\mathrm{P} \mid<\delta\right]-\operatorname{Pr}\left[\mathrm{P} \in \mathrm{I}^{\mathrm{c}}\right] \\
& =1-\eta / 2-\eta / 2 \\
& =1-\eta
\end{aligned}
\end{gathered}
$$

But $\eta$ is arbitrary and hence the result follows by letting

$$
\eta \rightarrow 0
$$

Lemma - 3: Fix D and let $\mathrm{a} \in(0,1)$, then there exists an $\mathrm{a}^{*}$ such that

$$
\mathrm{F}(\mathrm{PF})=\mathrm{E}(\mathrm{pv})
$$

Proof: Define:

$\mathrm{h}(\mathrm{a})=\mathrm{E}(\mathrm{PF})-\mathrm{E}(\mathrm{Pv})$

$$
=\mathrm{L}[\mathrm{F}(\min (\mathrm{Ri}, \mathrm{D})-(1-\mathrm{a}) \mathrm{F}(\mathrm{R})]
$$

Now $h(1) \operatorname{LE}\left(\min \left(\mathrm{R}_{\mathrm{i}}, \mathrm{D}\right)\right)>0$

and $\mathrm{h}(0)=\mathrm{L}\left[\mathrm{E}\left(\min \left(\mathrm{R}_{\mathrm{i}}, \mathrm{D}\right)-\mathrm{E}(\mathrm{R})\right]<0\right.$ since $\mathrm{F}\left(\mathrm{R}^{\mathrm{i}}\right)>\mathrm{E}\left(\min \left(\mathrm{R}_{\mathrm{i}} \mathrm{D}\right)\right.$

Furthermore, since $\mathrm{h}$ is continuous there exists an $\mathrm{a}^{*}$ such that

$$
\mathrm{h}\left(\mathrm{a}^{*}\right)=0 \text { as required. }
$$


Corollary - 1: For all a $<\mathrm{a}^{*}$ the lender strictly prefers the VRS.

Proof: Consider again $\mathrm{h}(\mathrm{a})$. Now for $\mathrm{h}(\mathrm{a})<0$ the VRS dominates whereas for $\mathrm{h}(\mathrm{a})>0$ the FRS dominates. Since $h\left(a^{*}\right)=0$ and $h(0)$ is a decreasing function of $a, h(a)<h\left(a^{*}\right)$ for all $a<a^{*}$.

Proposition - I: (Miller-Modigliani). If investors are risk neutral then the choice of a financial contract is irrelevant.

Proof: If investors are risk neutral then they look at their expected return from the two schemes. Now there exists $\left(D^{*}, a^{*}\right)$ such that

$$
\begin{aligned}
\mathrm{E}(\mathrm{PF}) & =\mathrm{E}(\mathrm{PV}) \\
\mathrm{E}(\mathrm{YF}) & =\mathrm{E}(\mathrm{YV})
\end{aligned}
$$

The existence is assured by the fact that both of the functions are continuous and by appropriately defining the joint map we can appeal to the fixed point theorem.

Thus the return across both of the contracts is the same for both the lender and the investor and as such there will be no preference for any of the two schemes. This means that the choice of the contract is irrelevant.

Proposition -2. Let

$$
\mathrm{S}^{*}(\mathrm{R}) \min (\mathrm{R}, \mathrm{D})
$$

and

$$
\mathrm{S}^{*}(\mathrm{R})=\max (\mathrm{R}-\mathrm{D}, 0)
$$

Fix a and pick D and $D^{\prime}$ so that $S^{*}(R)$ and $S_{*}(R)$ are a-sharing rules. Then for all concave utility functions $\mathrm{U}$ and any a-sharing rule $\mathrm{S}(\mathrm{R})$

$$
\mathrm{EU}\left(\mathrm{S}^{*}\right)>\mathrm{EU}(\mathrm{S})>\mathrm{EU}\left(\mathrm{S}^{*}\right)
$$

Proof: Let $\mathrm{A}=[\mathrm{S}(\mathrm{R}): \mathrm{ES}(\mathrm{R})=\mathrm{aE}(\mathrm{R}) ; 0<\mathrm{S}(\mathrm{R})<1]$

Thus A defines the class of a-sharing rules. Suppose also that $\mathrm{R}<\mathrm{M}$ where $\mathrm{M}$ is a sufficiently large constant.

The proof requires two things:

*) $\mathrm{EU}(\mathrm{S} *(\mathrm{R}))>\mathrm{EU}(\mathrm{S}(\mathrm{R}))$ for all $\mathrm{S}(\mathrm{R}) \in \mathrm{A}$ and $\mathrm{U}$ concave

**) $\mathrm{EU}(\mathrm{S} *(\mathrm{R}))<\mathrm{EU}(\mathrm{S}(\mathrm{R})) \quad$ for all $\mathrm{S}(\mathrm{R}) \in \mathrm{A}$ and $\mathrm{U}$ concave

i.e. $S *(R)$ is the upper bound and $S *(R)$ is a the lower bound for the Class $A$ under all concave functions.

Thus we will prove the above two statements separately. We will make use of the following two lemmas by Rothschild and Stiglitz (1970).

Lemma - $\boldsymbol{a}$ : Suppose $\mathrm{X}$ and $\mathrm{Y}$ are two random variables with the same expected value. $\mathrm{Y}$ is riskier (Or more variable) than $\mathrm{X}$ if any of three conditions are true:

i) $\mathrm{Y}=\mathrm{X}+\mathrm{Z}$ with $\mathrm{E}(\mathrm{Z} \mid \mathrm{X})=0$ and $\mathrm{X}$ and $\mathrm{Y}$ are identically distributed.

ii) $\mathrm{EU}(\mathrm{X})>\mathrm{EU}(\mathrm{Y})$ for all bounded and concave utility functions.

iii) If $f$ is the density of $X$ and $g$ is that of $Y$ then

$$
\begin{gathered}
g=f+s \\
\text { where } \int_{s}(x) d x=\int_{X s}(x) d x=0
\end{gathered}
$$

i.e. the density of $\mathrm{Y}$ can be obtained from that of $\mathrm{X}$ by a single mean-preserving spread. 
Lemma $\boldsymbol{b}$ : Let $\mathrm{G}$ be the distribution function of $\mathrm{Y}$ and $\mathrm{F}$ be the distribution function of $\mathrm{X}$. Define

$$
S(x)=G(x)-F(x)
$$

then $\mathrm{G}$ is riskier than $\mathrm{F}$ if $\mathrm{S}$ satisfies the following two conditions (called the integral conditions):

i) $T(1)=\int_{0}^{1} S(x) d x=0$

ii) $\mathrm{T}(\mathrm{y})=\int_{0}^{\mathrm{y}} \mathrm{S}(\mathrm{x}) \mathrm{dx}>0$ for all $0<\mathrm{y}<1$

Proof of (*): Suppose $\mathrm{S}^{*}(\mathrm{R})$ is not the most preferred payoff, rather $\mathrm{S}(\mathrm{R})$ has this property (such a payoff exists since $\mathrm{A}$ is a member of the bounded class of function). We will establish a contradiction.

and $0<\mathrm{S}(\mathrm{R})<\mathrm{R}$

Since $S(R) \in A$

$E S(R)=a E(R)$

Second, since $\mathrm{S}(\mathrm{R})$ is most preferred

and in particular we have

$\mathrm{EU}(\mathrm{S}(\mathrm{R}))>\mathrm{EU}\left(\mathrm{S}^{\prime}(\mathrm{R})\right)$ for all $\mathrm{S}^{\prime}(\mathrm{R}) \in \mathrm{A}$

$$
\mathrm{EU}(\mathrm{S}(\mathrm{R}))>\mathrm{EU}\left(\mathrm{S}^{*}(\mathrm{R})\right)
$$

Given that $U$ is concave (l) implies that $S(R)$ is less risky than $S^{*}(R)$ (by lemma-a above). Again by lemma-a (iii), this means that the distribution of $S^{*}(R)$ can be obtained from that of $S(R)$ through a single mean-preserving spread. Thus for (1) to be true the difference of the distribution functions of $S(R)$ and $S^{*}(R)$ should satisfy the integral conditions of lemma-b.

Thus we need to find the distribution functions of $S(R)$ and $S^{*}(R)$.

Let $\mathrm{F}(\mathrm{r})$ be the distribution function of $\mathrm{R}$ and $\mathrm{H}(\mathrm{r})$ be the distribution function of $\mathrm{S}^{*}(\mathrm{R})$, then

$H(r)=\left[\begin{array}{ll}0 & r<0 \\ F(r) & 0<r<D^{\prime} \\ 1-F\left(D^{\prime}\right) & D^{\prime}<r<M \\ 1 & M<r\end{array}\right.$

Define $\mathrm{S}(\mathrm{R})$ as follows:

$$
S(r)=\left[\begin{array}{l}
t_{1}(r) r<D^{\prime} \\
t_{2}(r) r>D^{\prime}
\end{array}\right.
$$

where, given $D^{\prime}, t_{1}(r)$ and $t_{2}(r)$ are chosen so that:

$$
\mathrm{ES}(\mathrm{R})=\mathrm{aE}(\mathrm{R}) \text { and } 0<\mathrm{S}(\mathrm{R})<\mathrm{R}
$$

Thus $\mathrm{S}(\mathrm{R})$ is an arbitrary payoff function that belongs to A.

Let $\mathrm{G}(\mathrm{r})$ be the distribution function of $\mathrm{S}(\mathrm{R})$. then:

$\mathrm{G}(\mathrm{r})=\left[\begin{array}{lc}0 & \mathrm{r}<0^{\prime} \\ \mathrm{F}\left(\mathrm{t}_{1}{ }^{-1}(\mathrm{r})\right) & 0<\mathrm{r}<\mathrm{D}^{\prime} \\ \mathrm{F}\left(\mathrm{t}_{2}{ }^{-1}(\mathrm{r})\right) & \mathrm{D}^{\prime}<\mathrm{r}<\mathrm{M} \\ 1 & \mathrm{M}<\mathrm{r}\end{array}\right.$

Finally, let: 


$$
\mathrm{K}(\mathrm{r})=\mathrm{H}(\mathrm{r})-\mathrm{G}(\mathrm{r})
$$

Thus we need to check if $\mathrm{K}(\mathrm{r})$ satisfies the integral conditions of lemma-b.

The first condition is trivially true since both of the payoffs belong to class A.

For the second condition let:

$$
\begin{aligned}
T\left(r^{\prime}\right) & =\int_{0}^{r^{\prime}} K(r) d r \\
& =\int_{0}^{r^{\prime}}[H(r)-G(r)] d r
\end{aligned}
$$

Thus it should be true that:

$$
\mathrm{T}\left(\mathrm{r}^{\prime}\right)>0 \text { for all } \mathrm{r}^{\prime} \in(0, \mathrm{M})
$$

Let $\mathrm{r}^{\prime}=\mathrm{D}^{\prime}$, then

$$
\begin{aligned}
T\left(D^{\prime}\right) & =\int_{0}^{D^{\prime}}[H(r)-G(r)] d r \\
& =\int_{0}^{D^{\prime}}\left[F(r)-F\left(t_{1}^{-1}(r)\right)\right] d r
\end{aligned}
$$

Since $\mathrm{F}$ is monotonic and $\mathrm{r}<\mathrm{t}_{1}{ }^{-1}(\mathrm{r})$ we have

$$
\mathrm{F}(\mathrm{r})<\mathrm{F}(\mathrm{t} 1-1(\mathrm{r}))
$$

$$
\mathrm{T}(\mathrm{r})=\int_{0}^{\mathrm{D}^{\prime}}\left[\mathrm{F}(\mathrm{r})-\mathrm{F}\left(\mathrm{t}_{1}^{-1}(\mathrm{r})\right)\right] \mathrm{dr}<0
$$

contradicting that $\mathrm{S}(\mathrm{R})$ is the most preferred a-sharing payoff.

Proof of $(* *)$ : Though a rigorous proof along the same lines of $(*)$ can be given, here we argue by a simple method that is fairly intuitive.

Since $S^{*}(R)$ is the most preferred payoff, the residual payoff should be the least preferred payoff. The residual payoff is given as:

$$
S^{\circ}(R)=\left[\begin{array}{ll}
0 & R<D \\
R-D & R>D
\end{array}\right.
$$

where $D$ is determined by the constraint that $S^{\circ}(R)$ must belong to A. But $S^{\circ}(R)=S^{*}(R)$ and as such

$$
\mathrm{EU}(\mathrm{S} *(\mathrm{R}))<\mathrm{EU}(\mathrm{S}(\mathrm{R})) \text { for all } \mathrm{S} \in \mathrm{A}
$$

Corollary - 2: A risk averse investor strictly prefers the VRS over the FRS.

Proof: we need to show that:

$$
\mathrm{EU}(\text { Yiv) }>\mathrm{EU}(\text { Yiv) }
$$

at the point where

$$
\mathrm{E}(\mathrm{Yiv})=\mathrm{E}(\mathrm{YiF})
$$

Note that both $\mathrm{Y}^{\mathrm{V}}$ and $\mathrm{Y}^{\mathrm{f}}$ are a-sharing rules since:

$$
\mathrm{E}(\mathrm{Yiv})=\mathrm{aE}(\mathrm{R})
$$

and both of these payoffs are bounded by M. Therefore the corollary follows by letting:

in proposition-2.

$$
\mathrm{S} *(\mathrm{R})=\mathrm{Y}^{\mathrm{F}}=\max \left(\mathrm{R}_{\mathrm{i}}-\mathrm{D}, 0\right)
$$

Theorem - 1. : Corresponding to each FRS there is a VRS which improves everyone's welfare. 
Proof: From Corollary-2 each investor prefers VRS. We show that the lender can be made better off through the VRS arrangement.

Since $\mathrm{U}$ is continuous there is an e positive such that:

$$
\mathrm{EU}\left\{\left(\mathrm{a}^{*}-\mathrm{e}\right)\right) \mathrm{R}=\mathrm{EU}\left(\max \left(\mathrm{R}_{\mathrm{i}}-\mathrm{D}, 0\right)\right\}
$$

Therefore it is possible to give, say, $1 / 2 \mathrm{R}_{\mathrm{i}}$ to the lender without changing the investor's preference for the VRS. From corollary-1. it follows that for $a=a^{*-1 / 2 e}$ lender strictly prefers the VRS. This shows that the VRS improves everyone's welfare.

\section{Appendix - 2}

Proposition - 1: Let $\left(\mathrm{p}^{\mathrm{v}}, \mathrm{Y}^{\mathrm{v}}, \mathrm{g}, \mathrm{h}, \mathrm{C}^{\mathrm{v}}\right)$ be the game defined above for the VRS. The Nash solution of the game is given by the pair:

$$
\left(g^{*}, h^{*}\right)=[r-b / 1-a, 1-\exp -\{(1-a)(1-g(r))-b\} / b]
$$

and minimizes the expected cost of monitoring.

Proof: The investor chooses $\mathrm{g}(\mathrm{r})$, for a given $\mathrm{h}(\mathrm{g}(\mathrm{r}))$, to maximize:

The first order condition is:

$$
\mathrm{Y}^{\mathrm{V}}=\mathrm{r}-(1-\mathrm{a}) \mathrm{g}(\mathrm{r})-\mathrm{h}(\mathrm{g}(\mathrm{r}))(1-\mathrm{a})(\mathrm{r}-\mathrm{g}(\mathrm{r}))
$$

$$
\begin{aligned}
& \frac{d Y^{v}}{d g(r)}=-(1-a)-h^{\prime}(g(r))(1-a)(r-g(r))+(1-a) h(g(r))=0 \\
& g(r)=r+\{1-h(g(r)))(r),\} / h^{\prime}(g(r))
\end{aligned}
$$

On the other hand the lender maximizes, for a given $g(r)$ :

$$
E\left(P^{v}\right)=\int_{d}^{1}\{(1-a) g(r)+h(g(r))[(1-a)(r-g(r))-b]\} m d r
$$

where $\mathrm{m}=1 / 1 \mathrm{~d}$.

This is equivalent to maximizing integrand in (2). We will justify this procedure below Since (2) is linear in $\mathrm{h}(\mathrm{g}(\mathrm{r}))$ for a given $\mathrm{g}(\mathrm{r})$, we have:

$$
h\left(g(r)=\left[\begin{array}{lll}
0 & \text { if } & (1-a)(r-g(r))<b \\
1 & \text { if } & (1-a)(r-g(r))>b
\end{array}\right.\right.
$$

A corner solution is clearly inefficient in terms of cost of monitoring. If lender has access to randomzed monitoring technology then he chooses $\mathrm{h}(\mathrm{g}(\mathrm{r}))$ such that:

$$
\mathrm{h}(\mathrm{g}(\mathrm{r})) \in(0,1) \text { and }(\mathrm{r}-\mathrm{g}(\mathrm{r}))=\mathrm{b} / 1-\mathrm{a}
$$

This is the Nash Equilibrium condition for the lender. But the problem is how to find $h(g(r))$ from (4)?

From (1):

$$
r-g(r)=-[1-h(g(r))] / h^{\prime}(g(r))
$$

So the Nash Solution is given by the two equilibrium conditions:

$$
\mathrm{r}-\mathrm{g}(\mathrm{r})=-[1-\mathrm{h}(\mathrm{g}(\mathrm{r}))] / \mathrm{h}^{\prime}(\mathrm{g}(\mathrm{r}))=\mathrm{b} / 1-\mathrm{a}
$$

From the second equation in (5) we get:

$\left[1-\mathrm{h}(\mathrm{g}(\mathrm{r})) \mathrm{h}^{\prime}(\mathrm{g}(\mathrm{r})=\mathrm{b} / 1-\mathrm{a}\right.$ 
$-(b / 1-a) h^{\prime}(g(r))+h(g(r))=1$

(6) is a linear differential equation which has the solution:

$$
\mathrm{h}^{*}(\mathrm{~g}(\mathrm{r}))=\mathrm{I}-\exp \{[-(1-\mathrm{a})(1-\mathrm{g}(\mathrm{r}))-\mathrm{b}] / \mathrm{b}\}
$$

where $h(1-b / l-a)$ is the initial condition. Note that the lender's optimal strategy does not have $r$ as its argument since he does not observe $r$. This justifies our procedure of maximizing the integrand in (2).

$\mathrm{h}^{*}(\mathrm{~g}(\mathrm{r}))$ forces $\mathrm{g}(\mathrm{r})$ to be:

$$
g^{*}(r)=r-b / 1-a
$$

It can be seen that $g^{*}(r)$ is invertible in $r$, but the reporting space $(0.1-b / 1-a)$ is different from $(d, 1)$, the original space. We see that $d=b / l-a$.

Thus we have shown that

$$
\left(\mathrm{g}^{*}, \mathrm{~h}^{*}\right)=[\mathrm{r}-\mathrm{b} / 1-\mathrm{a}, 1-\exp \{[-(1-\mathrm{a})(1-\mathrm{g}(\mathrm{r}))-\mathrm{b}] / \mathrm{b}\}]
$$

is Nash equilibrium solution of the game under the VRS.

It remains to be shown that this also minimizes the expected monitoring Costs.

Given $\left(g^{*}, h^{*}\right)$ :

$$
\begin{aligned}
\mathrm{E}\left(\mathrm{C}^{\mathrm{v}}\right) & =\int_{0}^{1-\mathrm{b} / \mathrm{l}-\mathrm{a}} \mathrm{b}[1-\exp \{-[(1-\mathrm{a}) \mathrm{g}(\mathrm{r})-\mathrm{b}] / \mathrm{b}\}] \operatorname{mdg}(\mathrm{r}) \\
& =\mathrm{b}[1-(\mathrm{b} / 1-\mathrm{a}-\mathrm{b})(1-\exp -(1-\mathrm{a}-\mathrm{b}) / \mathrm{b})]
\end{aligned}
$$

Thus $\mathrm{E}\left(\mathrm{C}^{\mathrm{V}}\right)<\mathrm{b}$. The only other equilibrium is $\mathrm{h}(\mathrm{g}(\mathrm{r}))=1$. But then $\mathrm{F}\left(\mathrm{C}^{\mathrm{v}}\right)=\mathrm{b}$. Thus $\left(\mathrm{g}^{*}, \mathrm{~h}^{*}\right)$ minimizes the monitoring costs

Proposition - 2: Let $\left(\mathrm{P}^{\mathrm{F}}, \mathrm{Y}^{\mathrm{F}}, \mathrm{g}, \mathrm{h}, \mathrm{C}^{\mathrm{F}}\right)$ be the game defined above for the FRS The Nash Solution of the game is given by:

$$
\left(\mathrm{g}^{*}, \mathrm{~h}^{*}\right)=[\min (\mathrm{r}, \mathrm{D})-\mathrm{b}, 1-\exp \{-(\mathrm{D}-\mathrm{g}(\mathrm{r})-\mathrm{b}) / \mathrm{b}\}]
$$

and minimizes the expected cost of monitoring.

Proof: In this case the investor chooses $g(r)$ for a given $h(g(r))$, to maximize:

$$
\mathrm{Y}^{\mathrm{F}}=\mathrm{r}-\mathrm{g}(\mathrm{r})-\mathrm{h}(\mathrm{g}(\mathrm{r}))[\min (\mathrm{r}, \mathrm{D})-\mathrm{g}(\mathrm{r})]
$$

Maximizing (9) over $\mathrm{g}(\mathrm{r})$ gives:

which gives:

$$
\left.\frac{d Y^{F}}{d g(r)}=-1-h^{\prime}(g(r))[\min (r, D)-D)-g(r)\right]+h(g(r))=0
$$

$$
\mathrm{g}(\mathrm{r})=\min (\mathrm{r} . \mathrm{D})+[1-\mathrm{h}(\mathrm{g}(\mathrm{r}))] / \mathrm{h}^{\prime}(\mathrm{g}(\mathrm{r})
$$

On the other hand the lender maximizes, for a given $\mathrm{g}(\mathrm{r})$ :

$$
E\left(P^{F}\right)=\int_{d}^{1}[g(r)+h(g(r))\{\min (r, D)-g(r)-b\}]
$$

As we argued in Proposition-1, this is equivalent to maximizing the integrand in (11). Since (11) is 
linear in $h(g(r))$, we get:

$$
h(g(r))=\left[\begin{array}{ll}
0 & \text { if } \min (r, D)<b \\
1 & \text { if } \min (r, D)>b
\end{array}\right.
$$

Again a corner solution is inefficient in terms of cost of monitoring. If the lender has access to a randomized technology he will choose $\mathrm{h}(\mathrm{g}(\mathrm{r}))$ so that:

$$
\mathrm{h}(\mathrm{g}(\mathrm{r}) \in(0,1) \text { and } \min (\mathrm{r}, \mathrm{D})-\mathrm{g}(\mathrm{r})=\mathrm{b}
$$

This is the Nash Equilibrium condition for the lender under the FRS. Now combining (10) and (13), we get:

$$
\min (r, D) g(r)=-[1-h(g(r))] / h^{\prime}(g(r)=b
$$

From the second equation in (14) we get:

$$
-b^{\prime}(g(r))=h(g(r))=1
$$

(15) is a linear differential equation having the solution

$$
h^{*}(g(r))=1-\exp \{-[D-g(r)-b] / b\}
$$

where we have imposed the initial condition:

$$
h(D-b)=0
$$

On the other hand the optimal $\mathrm{g}(\mathrm{r})$ is given as:

$$
\mathrm{g} *(\mathrm{r})=\min (\mathrm{r}, \mathrm{D})-\mathrm{b}
$$

It is easy to show in the same way as in Proposition-1 that this Nash equilibrium minimizes the cost of monitoring.

Proposition - 3: Given a uniform distribution of return R and (1 - a) and D, such that:

$$
\mathrm{E}\left(\mathrm{P}^{\mathrm{F}}\right)=\mathrm{E}\left(\mathrm{P}^{\mathrm{V}}\right)
$$

with no monitoring costs, then the expected monitoring costs under the VRS are greater than under the FRS.

Proof: The expected costs for the VRS are given by:

$$
\mathrm{E}\left(\mathrm{C}^{\mathrm{V}}\right)=\mathrm{b}[1-(\mathrm{b} / 1-\mathrm{a}-\mathrm{b})[1-\exp \{-(1-\mathrm{a}-\mathrm{b}) / \mathrm{b}\}]]
$$

while under the FRS the costs are given by:

We need to show that:

$$
\mathrm{E}\left(\mathrm{C}^{\mathrm{F}}\right)=(\mathrm{b} / 1-\mathrm{b})[\mathrm{D}-\mathrm{b}(2-\exp \{-(\mathrm{D}-\mathrm{b}) / \mathrm{b}\})]
$$$$
b[1-(b / 1-a-b)[1-\exp \{-(1-a-b) / b\}]]>(b / 1-b)[D-b(2-\exp \{-(D-b) / b\})]
$$$$
1-(b / 1-a-b)[1-\exp \{-(1-a-b) / b\}]>D-b(2-\exp \{-(D-b) / b\})
$$

since $\mathrm{D}<1$

$$
(b / 1-a-b)[1-\exp \{-(1-a-b) / b\}]>b(2-\exp -(D-b) / b)
$$

$$
\begin{aligned}
& 1-\exp \{-(1-a-b) / b<2-\exp \{-(D-b) / b\} \text { since } 1-a-b<1 \\
& \exp \{-(1-a-b) / b\}>\exp \{-(D-b) / b\}-1
\end{aligned}
$$

Since $0<\exp (-\mathrm{k})<1$ for all non-negative $\mathrm{k}$, (17) is true for all a D, and $\mathrm{b}$. This means that in particular it is true for the pair $(\mathrm{a}, \mathrm{D})$ such that:

$$
\mathrm{E}\left(\mathrm{P}^{\mathrm{V}}\right)=\mathrm{F}\left(\mathrm{P}^{\mathrm{F}}\right) \text { with no information costs. }
$$

Lemma - 1: Let $(1-\mathrm{a}),\left(1-\mathrm{a}^{\prime}\right), \mathrm{D}$ and $\mathrm{D}^{\prime}$ denote the share and fixed return of the lender without and 
with the information costs. Then if the lender equalizes his return across two schemes under both situations then:

and

$$
\mathrm{a}^{\prime}<\mathrm{a}
$$

$$
\mathrm{D}^{\prime}>\mathrm{D}
$$

Proof: The payoff to the lender under the FRS with information costs is:

$$
\left.E\left(P^{\prime F}\right)=(1 / 1-b)\left[D(1-1 / 2 D)-1 / 2 b^{2}\right)\right]-b
$$

while the payoff to the lender under the FRS with no information costs is:

$$
\mathrm{E}\left(\mathrm{P}^{\mathrm{F}}\right)=(1 / 1-\mathrm{b})\left[\mathrm{D}(1-1 / 2 \mathrm{D})-1 / 2 \mathrm{~b}^{2}\right]
$$

equalizing (18) and (19) we get:

\section{or}

Since $b(1-b)>0$ we have:

$$
D^{\prime}\left(1-\frac{1}{2} D^{\prime}\right)-b(1-b)=D(1-1 / 2 D)
$$

$$
D^{\prime}\left(1-1 / 2 D^{\prime}\right)=D(1-1 / 2 D)+b(1-b)
$$

$$
\mathrm{D}^{\prime}>\mathrm{D}
$$

On the other hand the lender's payoff under the VRS with and without the information costs are:

$$
\begin{aligned}
& \mathrm{E}\left(\mathrm{P}^{\prime \mathrm{V}}\right)=1 / 2\left(1-\mathrm{a}^{\prime}\right)\left[1+\mathrm{b} / 1-\mathrm{a}^{\prime}\right]-\mathrm{b} \\
& \mathrm{E}\left(\mathrm{P}^{\mathrm{V}}\right)=1 / 2(1-\mathrm{a})[1+\mathrm{b} / 1-\mathrm{a}]
\end{aligned}
$$

respectively.

Equalizing (20) and (21) we get:

$$
\left(1-a^{\prime}\right)=(1-a)+2 b / 1+b(1-b)
$$

Since $\mathrm{b} / 1+\mathrm{b}(\mathrm{l}-\mathrm{b})>0$, we have $\left(1-\mathrm{a}^{\prime}\right)>(1-\mathrm{a})$ or $\mathrm{a}^{\prime}<\mathrm{a}$ as required.

Proposition - 4: The choice of the financial contract depends on the investor's attitude towards risk. For sufficiently low degree of risk aversion the FRS dominates the VRS.

Proof: It is clear that in order to determine the investor's choice of the contract we have to look at his expected utility under the two contracts. Thus the choice of a contract depends on the degree of risk aversion. The proof of exact dependence is fairly tedious as such we ignore it here. We show the dominance of the FRS under the linear case.

The proof follows from Proposition-3 and Lemma-1. From Proposition-3 we know that expected monitoring costs are higher for the VRS and Lemma-1 establishes the transfer of these costs to the investors. Since the payoff to the lender is equalized across both schemes and in both situations, the investors would ultimately bear these monitoring Costs. But these costs are smaller in the case of the FRS since there is a smaller deadweight loss. Therefore the investor's payoff is higher under the FRS and he would accordingly prefer the FRS over the VRS. 
نخو نظام اقتصادي لاربوي إسلامي

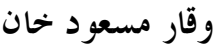

كبير الاقتصاديين، ونائب رئيس مؤسسة بانكرز إكويتي ليميتد - كراتشي مدي

المستخلص : يستخدم البحث أدوات التحليل الرياضي المتعمقة ليقارن نظامًا ماليًا إسـلاميًا

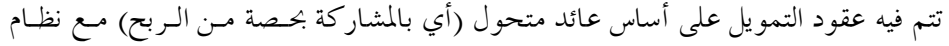

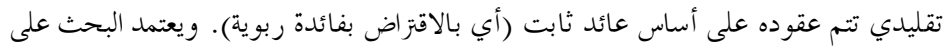

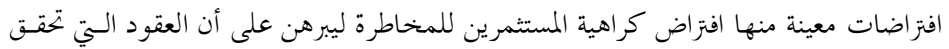

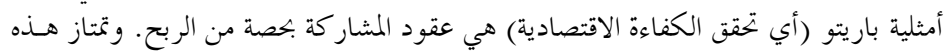

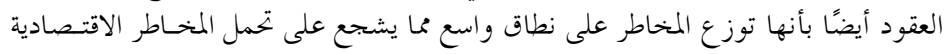

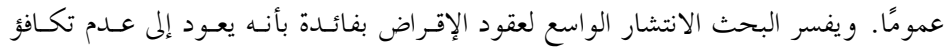

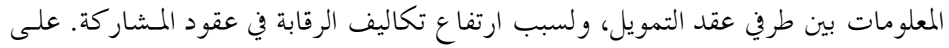

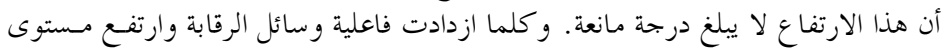
الأمانة لدى رجال الأعمال كلما ظهر تفوق نظام التمويل الإسلاميل الإمي عمليًا. 